\title{
Stressors and Coping Behaviors of Female Peer Leaders Participating in College Club Sports
}

\author{
Leigh A. Bryant \\ West Virginia University
}

Follow this and additional works at: https://researchrepository.wvu.edu/etd

\section{Recommended Citation}

Bryant, Leigh A., "Stressors and Coping Behaviors of Female Peer Leaders Participating in College Club Sports" (2013). Graduate Theses, Dissertations, and Problem Reports. 648.

https://researchrepository.wvu.edu/etd/648

This Thesis is protected by copyright and/or related rights. It has been brought to you by the The Research Repository @ WVU with permission from the rights-holder(s). You are free to use this Thesis in any way that is permitted by the copyright and related rights legislation that applies to your use. For other uses you must obtain permission from the rights-holder(s) directly, unless additional rights are indicated by a Creative Commons license in the record and/ or on the work itself. This Thesis has been accepted for inclusion in WVU Graduate Theses, Dissertations, and Problem Reports collection by an authorized administrator of The Research Repository @ WVU. For more information, please contact researchrepository@mail.wvu.edu. 
Stressors and Coping Behaviors of Female Peer Leaders Participating in College Club Sports

Leigh A. Bryant, B.A.

Thesis submitted to the College of Physical Activity and Sport Sciences at West Virginia University

in partial fulfillment of the requirements for the degree of

Master of Science in Sport \& Exercise Psychology

Damien Clement, Ph.D., ATC, Chair Vanessa Shannon, Ph.D. Ed Jacobs, Ph.D.

Department of Sport Sciences

Morgantown, WV

2013

Keywords: stress, coping, peer leadership, women, college athletes, club sports Copyright 2013 Leigh A. Bryant 


\begin{abstract}
Stressors and Coping Behaviors of Female Peer Leaders Participating in College Club Sports

Leigh A. Bryant

Peer leadership positions on collegiate club sport teams can be valuable opportunities for students to develop leadership skills, maintain healthy habits, create friendships, and foster organizational and personal connections across the university setting. Nevertheless, involvement in club sports can create stress over and above the many stressors that college students may encounter during their undergraduate experience. This study focused on exploring female leaders' perceived stressors inside and outside of the sport setting, and the ways in which they coped with them. Participants $(N=7)$ were interviewed based on nominations from their respective teammates. Interviews were conducted using a semi-structured interview guide. Results revealed that female club sport athletes in this sample indicated stress across many domains, including social, academic, and athletic. The use of emotion-focused strategies to cope with stress was particularly evident, with participants describing strategies such as sleeping, avoiding, or praying much more frequently than strategies like seeking professional help or advice. Each stressor and strategy identified by the participants is discussed, with specific emphasis placed on the adjustment to college, issues during college, and gender differences in coping. Practical implications and ideas for future research are also explored.
\end{abstract}




\section{ACKNOWLEDGMENTS}

I would like to thank my Committee Chair, Dr. Damien Clement, for his feedback and encouragement throughout the entire master's thesis process.

I would also like to thank the other members of my committee, Dr. Vanessa Shannon and Dr. Ed Jacobs, for the time and energy they put into helping me complete this project.

A big thank-you goes to the faculty members and students in the Sport \& Exercise Psychology and Counseling programs here at WVU.

I'd like to think that writing a thesis with a workmate is better than writing one alone. Thanks to Mike Berrebi for your friendship. And thanks to Pete Kadushin for all of the high-fives.

Finally, thanks to Mom, Dad, Kurt, and Zinta for your constant love and support. 


\section{TABLE OF CONTENTS}

Page \#

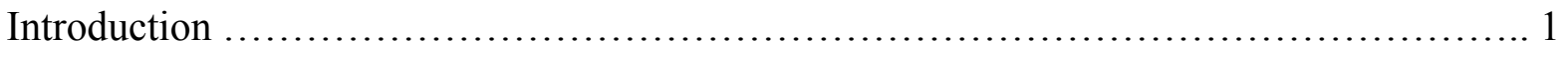

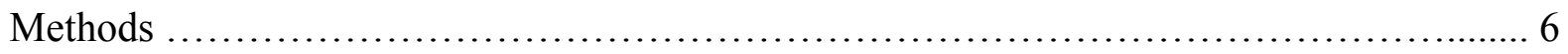

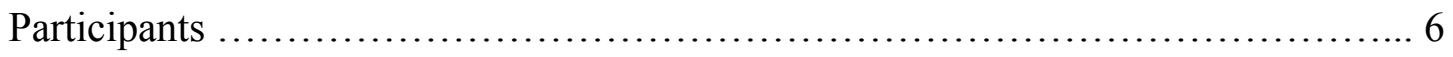

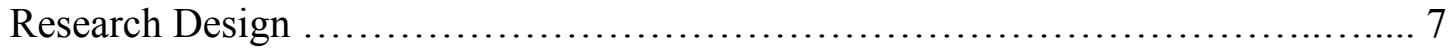

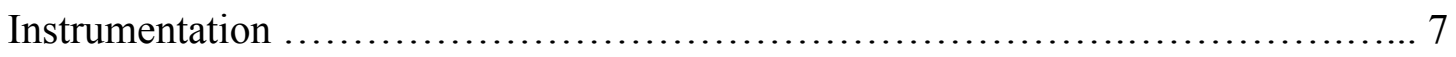

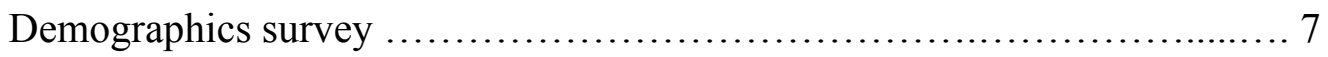

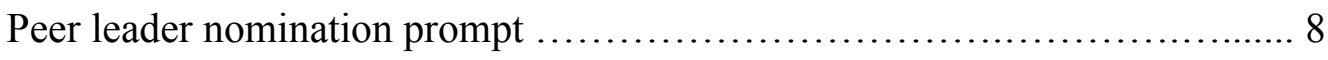

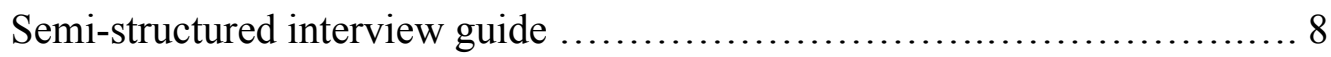

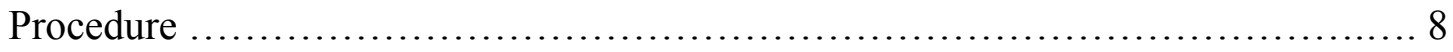

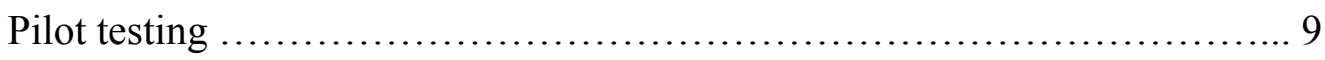

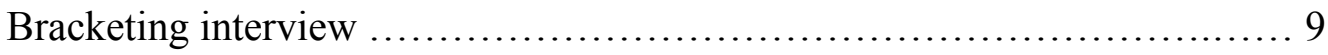

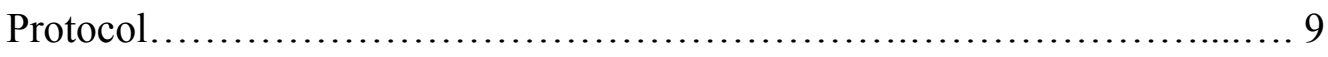

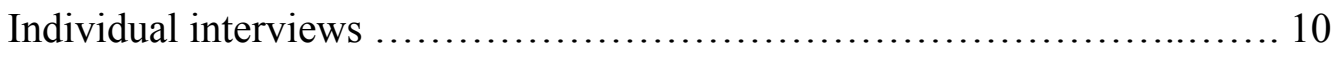

Data Analysis ................................................................. 11

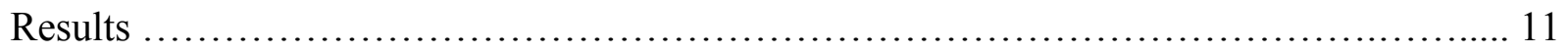

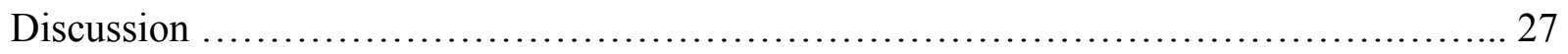

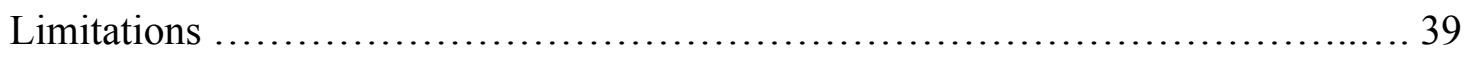

Practical Implications and Future Research ................................... 40

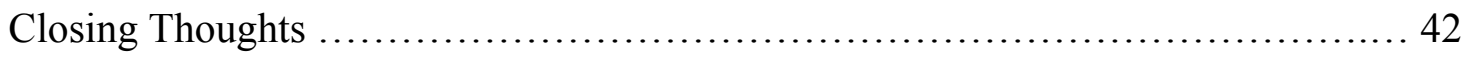

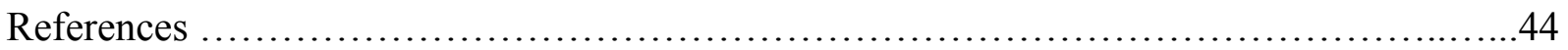




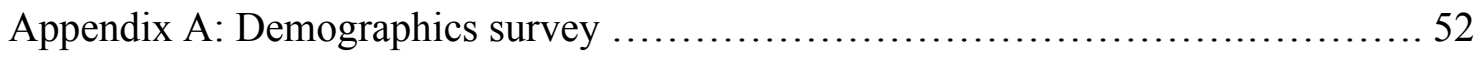

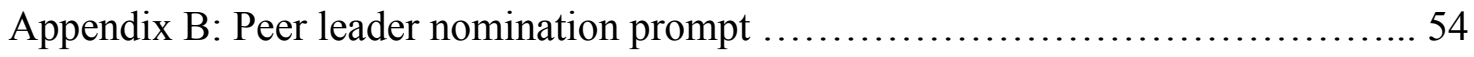

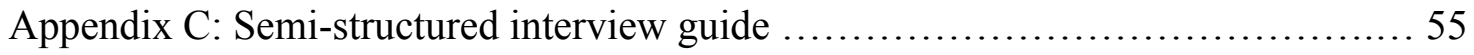

Appendix D: Cover letter to participants ................................... 56

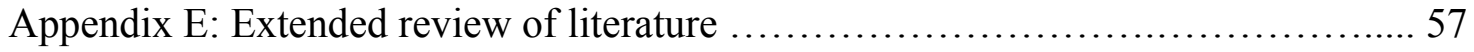




\section{Introduction}

Club sports are defined by the National Intramural Recreational Sports Association (NIRSA) as groups of students who come together voluntarily to organize and "further their common interests in an activity through participation and competition... [and] student leadership, interest, involvement, and participation... should be a learning experience for the members" (Roberts, Miller, \& Wells, 2003, p. 11). Across the United States, approximately two million college students are strapping on their shin guards or preparing for their next serve, all the while fostering friendships and an active lifestyle (Pennington, 2008). Although club and varsity athletes may appear to have similar intrapersonal, health, and social goals, varsity athletes often have much more streamlined, focused roles as competitors in comparison to club sport athletes (e.g., Lifschutz, 2012; Pennington). Club sport athletes, on the other hand, are frequently faced with more administrative and social responsibilities when compared to varsity athletes; the added burdens of self-organization, scheduling, dealing with team conflicts, and coordinating members with diverse needs and interests makes this population unique (Lifschutz).

Despite the uniqueness of the club sports population, research with such athletes is limited in the sport sciences. It is important for scholars and practitioners alike to recognize the potential gains or benefits that could come from conducting research with such a population. For scholars, increased research with club sports athletes could better inform the practices of coaching and consulting at the club sports level. For practitioners, the training and supervision of sport psychology consultants could increase among club sports, particularly in cases where university athletics programs do not have open placements for graduate students seeking consultation hours. Additionally, because some club sport athletes may have considered competing at the college varsity level before choosing otherwise, the overall intensity or passion, 
athletic skill, and technical knowledge could likely be further enhanced when club sport participants are provided with the attention and resources needed to promote performance excellence and the application of effective life skills.

Notwithstanding the aforementioned responsibilities of club sport athletes in comparison to varsity athletes, the leadership skills gained through club sports participation have been recognized as an important positive outcome in the literature (e.g., Lifschutz, 2012). The opportunity to be involved in club sports and, more importantly, to serve as a peer leader in this setting may help students to cultivate leadership skills that they can potentially apply to other life pursuits (e.g., Gould \& Carson, 2008). Peer leaders, also referred to as team leaders, are individuals who formally, or informally, occupy a leadership role on their respective athletic teams (e.g., Dupuis, Bloom, \& Loughead, 2006; Voelker, Gould, \& Crawford, 2011). Although peer leadership has recently been explored in the sport science literature (e.g., Loughead \& Hardy, 2005), there is little known about the stressors that peer leaders experience inside and outside of sport, and the ways in which they cope with them.

The topic of stress has been thoroughly explored in a wide variety of populations and settings (e.g., Nicholls \& Polman, 2007). More specifically, literature exists on the relationships between stress and illness (e.g., Yi, Smith, \& Vitaliano, 2005) and stress and injury (e.g., Andersen \& Williams, 1988), to name a few areas of focus. Researchers have determined that stress is a common occurrence amongst college students due to the many demands they face while experiencing a shift in environs, peer groups, and identities (e.g., Medalie, 1981; Ross, Niebling, \& Heckert, 1999). As stated by Chao (2011), college students' perceived stress “can be attributed to a multitude of... stressors, ranging from academic difficulties to uncertainty about the future, conflicts with friends, or problems with dating" (p. 338). Moreover, Chao has 
suggested that constant, daily stressors may be particularly harmful to students' well-being, potentially due to their chronic nature. These constant, everyday stressors are often called "daily hassles," and can be measured via self-report surveys and checklists (e.g., Holm \& Holroyd, 1992). In contrast to these everyday stressors, some researchers have focused on life events as indicators of substantial stress (e.g., Sarason, Johnson, \& Siegel, 1978). Both measures, daily hassles and life events, have produced interesting and important results. It must be stated, though, that researchers have often found daily hassles to be more strongly related to health outcomes and subjective well-being than major life events in younger samples, such as adolescents (Folkman, Lazarus, Pimley, \& Novacek, 1987).

According to the respective literatures on club sports (e.g., Lifschutz, 2012; Roberts et al., 2003) and stress (e.g., Chao, 2011; Lazarus \& Folkman, 1984), collegiate club sport athletes are likely to experience and cope with several demands in areas outside of sports, including the intrapersonal, academic, romantic, and social domains. As is evidenced through research, minimizing stress as a result of major life events and/or daily hassles may prevent the onset of chronic stress and anxiety (e.g., Kanner, Coyne, Schaefer, \& Lazarus, 1981; Ross et al., 1999). Continued exploration across multiple domains can be used to highlight the shared stressors experienced and subsequent strategies used to deal with them within the club sports population (e.g., Medalie, 1981; Nicholls \& Polman, 2007). Identifying and improving upon the coping strategies used to deal with stress, and the emotions associated with stress, may potentially contribute to an increase in club sport participants' overall well-being and performance (e.g., Lazarus, 2000).

The ability to cope with stress and overcome adversity is an important quality or skill for athletes to have (Nicholls, Polman, Morley, \& Taylor, 2009), and this could potentially include 
those who participate at the club sport level. Researchers have investigated the relationship between stress and coping (e.g., Carver \& Scheier, 1994; Lazarus \& Folkman, 1984; Yi et al., 2005), as well as the link between coping and coping strategies (e.g., Nicholls \& Polman, 2007) in both athlete and non-athlete populations. Nicholls and Polman explained that coping strategies are often classified into two larger, hierarchical categories that contain within them many different, related coping strategies. These two categories are problem-focused coping and emotion-focused coping; the former refers to the collection of coping strategies used when individuals attempt to change a perceived stressful situation, whereas the latter encompasses the strategies used when individuals attempt to deal with the emotional distress related to stressful situations (Nicholls \& Polman). Such classifications can help to organize and interpret various coping behaviors employed to deal with stress and stressful situations. Nevertheless, coping is a complex topic that is influenced by a number of factors.

One factor that has been shown to influence coping is gender (Nicholls et al., 2009). Specifically, researchers have suggested that gender is a distinguishing factor between particular categories of coping behavior (e.g., Crocker \& Graham, 1995; Nicholls, Polman, Levy, Taylor, \& Cobley, 2007; Ptacek, Smith, \& Zanas, 1992). For example, Ptacek et al. found that the males in their sample of undergraduate college students $(N=186)$ utilized problem-focused coping as their first strategy $56 \%$ of the time when faced with stress, compared to the females in the same sample, who used problem-focused coping as their primary method $44 \%$ of the time. This particular finding provides evidence that females may be more inclined to use emotion-focused coping in comparison to problem-focused coping when faced with stressful experiences. Therefore, it remains important for researchers, practitioners, and coaching staffs alike to better 
understand the possibility of gender differences in cognitions and behaviors among their athletes in order to best serve their specific group(s).

Additionally, in a study focused on recreational sport benefits and participant satisfaction, Lindsey (2012) found a statistically significant gender difference in the perceived benefit of stress reduction via involvement in campus recreational sports in a sample of undergraduate students $(N=161)$. Specifically, the researcher found that males reported perceiving higher levels of stress reduction as a result of participating in sports on average $(M=3.14, S D=0.14)$ than did females $(M=2.79, S D=0.07)$ (Lindsey). Findings like this reinforce the notion that gender differences may be vital to the approach that practitioners take when working with athletes in sport-related contexts. These findings also serve as the impetus for selecting only females as participants in the present study.

Based on the above mentioned, club sport athletes appear to be a unique population. The fundamental feature of club sports is self-governance, and therefore several athletes whom are involved in such groups will be responsible for organizing, managing, and executing various participants and events year-round. With these additional roles and responsibilities required, peer leaders in club sports may be at risk for experiencing relatively high levels of perceived stress compared to non-athletes and/or varsity athletes; in many cases, the latter group is provided adult assistance with travel, training, and finances. As such, the coping strategies that club sport peer leaders use are thus important to identify and improve upon so that these individuals can continue to thrive in the college environment. Moreover, because coping behaviors may differ between men and women, attention to gender differences and their implications may be critical to understanding and better supporting club sport athletes who are experiencing stress. 
Furthermore, since club sport athletes commonly lack the administrative infrastructure and professional support provided to varsity athletes (e.g., Lifschutz, 2013), the ability to be highly resourceful and creative in problem-solving and stress-reducing methods is paramount to these individuals and their team wellness (e.g., Humphrey, Yow, \& Bowden, 2000). Filling a gap in the literature on club sport athletes and their needs and characteristics related to stress and coping would be extremely beneficial to individuals who may work with this population in both the academic and applied settings. Therefore, the purpose of this study was to identify the stressors that female collegiate club sport peer leaders experience and to understand the ways in which they attempt to cope with stress.

\section{Methods}

\section{Participants}

Participants $(N=7)$ were female athletes $\left(M_{\mathrm{age}}=20.57, S D=0.98\right)$ participating in club sports at a Mid-Atlantic university during the 2012-2013 academic calendar year. They were all sophomore, junior, or senior status. None of the participants reported being engaged or married; martial status was presumed to be informative, given that engaged or married college women may perceive a different set of stressors than their single peers. Participants reported training 10.86 hours per week on average $(S D=9.15$ hours $)$, and had been involved in their sport for an average of 9.14 years $(S D=5.73$ years $)$. When asked for their current level of stress experienced in their respective club sports, participants indicated being moderately stressed $(M=4.29, S D=$ 1.50) on a 7-point Likert scale. Participants also reported talking to friends $(n=5)$, parents or siblings $(n=5)$, significant others $(n=3)$, academic mentors $(n=2)$, therapists/counselors $(n=$ $2)$, coaches $(n=2)$, and peer/team leaders $(n=1)$ when dealing with stress-related issues. 
All seven women identified themselves as leaders on their respective teams. Across interviews, participants cited their position or title, experience, age, and/or skill level as major factors contributing to their leadership status or level of recognition. Only females were identified as participants in the present study given that researchers have suggested that gender differences exist in coping (e.g., Anshel, Sutarso, \& Jubenville, 2009; Nicholls \& Polman, 2007). Additional selection criteria included age (18-22 years), collegiate status, and length of club sport membership (at least one season). Given the exploratory nature of the study, the researcher used convenience sampling and purposive sampling.

\section{Research Design}

The researcher conducted this study within a post-positivist paradigm (Patton, 2002). According to Mertens (2005), post-positivists generally suppose that a reality exists, but that it can only be known through an imperfect lens because all humans have limitations and biases. In the case of the present study, "the theories, hypotheses, and background knowledge" of the researcher may be considered filters through which the instrumentation, procedure, and results were selected and presented (Mertens, 2005, p. 11). Thus, an emphasis on objectivity (e.g., bracketing interview, quantifying participant experiences) was evident throughout the study.

\section{Instrumentation}

Demographics survey. The researcher used a self-constructed demographics survey (see Appendix A) to help characterize the sample and contribute to the understanding of the athletes' individual similarities and differences. Items on the demographics survey included age, marital status, year in college, number of years of sport experience, average number of hours of training per week, and history of seeking help for stress-related issues. The only identifying piece of 
information solicited from participants was their names, which were needed in order to gain access to university email accounts for sending individuals follow-up interview invitations.

Peer leader nomination prompt. There was one appended prompt to the demographics survey (see Appendix B). The prompt allowed participants to indicate to the researcher the person on their team who may be considered a peer leader. The names collected via this prompt allowed the researcher to contact potential participants for interviews within one to four weeks of the final demographics survey distribution to club sports teams.

Semi-structured interview guide. The semi-structured interview guide used to conduct individual interviews with peer-nominated leaders (see Appendix C) contained five questions, and was constructed from a variety of research articles in the literature (e.g., Anshel, 1996; Anshel \& Sutarso, 2007; Gaudreau \& Blondin, 2002). The interview guide was reviewed by a university professor trained in qualitative research prior to being used for the bracketing interview, pilot testing, and individual interviews. During the interviews, each participant was asked every question, with short, additional prompts inserted where/when necessary. Interviews lasted approximately 40 minutes on average, with a total range of 25 to 55 minutes of relevant conversation. A semi-structured interview guide was deemed most appropriate for this study given the existing literature on stress and coping, which in turn prompted the development of specific questions intended to further explore these constructs.

\section{Procedure}

The primary researcher first submitted and received approval for the study through the Institutional Review Board. Before any club sport athletes were contacted for potential involvement in the study, the researcher engaged in pilot testing and bracketing. These 
procedures helped to lay the foundation for the study and provided opportunities for interview practice and self-reflection.

Pilot testing. Pilot testing of the semi-structured interview guide occurred with a former undergraduate student $(N=1)$ who served as a peer leader on her club sports team during the previous academic year. Using typological analyses (Patton, 2002), the researcher practiced identifying themes and subthemes from the transcription, and conferred with a research advisor about these findings. This interview also allowed the researcher to improve specific interview skills such as building rapport and using appropriate probes.

Bracketing interview. Prior to conducting the interviews, the primary researcher participated in a bracketing interview (Fischer, 2009; Patton, 2002). The purpose of the bracketing interview was to allow the researcher to identify, and gain insight related to, personal experiences in sport, and to acknowledge prior participation as a leader on teams, in workshops, and within the context of athletics in general. An advanced doctoral student with interviewing and qualitative research experience conducted the bracketing interview. This helped to heighten the researcher's awareness of any presuppositions, expectations, and biases that could be recognized, accepted, and resolved for the remainder of the study. A graduate faculty member then reviewed the transcription of the bracketing interview with the researcher; several ideas, and preliminary themes and subthemes, were discussed.

Protocol. Following pilot testing and the bracketing interview, the researcher contacted the director of intramural sports at the university and attended a club sports meeting to seek participants and explain the major aims of the study. At this meeting, those club sports teams that were interested in the study set up dates and times to meet individually with the researcher at convenient locations. Each participant received a cover letter (see Appendix D) that explained 
the major aims of the study and what would be expected of her if she chose to participate. If consent was given, participants completed the demographics survey and the peer leader nomination prompt. The participants returned all materials on location. Participants were informed that they had the right to abstain from the study and/or terminate their involvement at any time without penalty or affecting team status.

Individual interviews. The peer leader nomination prompt that followed the demographics survey allowed the researcher to gather and select participants to be considered for follow-up interviews (Patton, 2002). These athletes were invited to participate in interviews with the primary researcher in a private, comfortable location (e.g., consulting room or office) or over the phone at a predetermined date and time. Seven out of nine individuals ultimately completed interviews. All interviews were audio-recorded and then transcribed by primary researcher; interview transcripts were saved as Word documents via Microsoft Office Word for Mac 2011 (Version 14.2.4). Hard-copy records with identifying and/or sensitive information were kept in a locked office and stored on a password-protected computer when converted to electronic documentation for data analyses. All transcripts were coded following the guidelines suggested by Creswell (2007), Miles and Huberman (1994), and Patton (2002).

Given the likelihood and possibility of human error or misinterpretation, the researcher and interviewees engaged in the process of member-checking (Patton, 2002). This process allowed participants to clarify for the researcher any unclear statements made during their interviews, add anything else they neglected to mention, and catch any mistakes that may have gone unnoticed during the transcription process. Participants had one week to respond via email. Three out of seven women responded, and none requested changes to their respective transcripts. 


\section{Data Analysis}

A typological approach was selected for the present study in order to best identify the stressors and coping strategies discussed by the participants. Therefore, the researcher coded each of the seven interview transcripts with respect to these two constructs. The researcher also engaged in data triangulation with a trained research assistant and a university faculty member familiar with qualitative interviewing and methods (Patton, 2002). The three research team members determined preliminary themes expressed in each interview as they related to stressors and coping strategies, and then selected quotes that most accurately represented these themes. It should be noted that coding was comprehensive; the researcher chose to present all stressors and coping strategies identified by participants, rather than present only those stressors or strategies that were reported by the majority. Qualitative researchers have discussed the value of giving all participants a voice (e.g., Denzin \& Lincoln, 2005) in contrast to seeking to achieve consensus.

\section{Results}

\section{Stressors}

The stressors most commonly described by participants during the interview process included academic stressors, sport-related stressors, social stressors, and the transition to college. In the following section, each category of stressor is supported by relevant quotes taken from participant interview transcripts.

Academic stressors. Exams, grades, and the overall demands of college academics were identified as particularly stressful issues and events for all seven interviewees. Courtney described her distaste for multiple-choice questions on exams, given that she struggles to perform well via this exam format: 
I mean with classes... I hate multiple-choice exams; I never do well on them no matter how much I study... so just with those and receiving not so satisfactory grades that sort of stressed me out a bit... um but I went to my professors and talked to them and I ended up doing fairly well this semester... that was another stressful thing. (Courtney)

Bethany explained that a break-up with a boyfriend led to a poor performance on an exam. Consequently, she had to study extra-hard for the remainder of the course in order to make up for it:

So I did really bad on that test [after a break-up] so that was really stressful because for the rest of the semester I had to spend time trying to make up that grade so I could pass the class. (Bethany)

Julie also cited academics as a source of stress. However, instead of grades or exams being the focus, Julie described her ongoing struggle with the challenging subject matter of mathematics, especially when she has little time to complete the work:

I'd probably say I struggle with math... it's one of the things I have to work on and study for... I had to take an accounting class and I remember like... it was so stressful to get through the semester... each week we had like homeworks online and they were timed and graded for accuracy, so it was really stressful, and not to mention we [my friends] would always wait until the last second which wasn't smart... if I hadn't waited I wouldn't have been as stressed. (Julie)

Sport-related stressors. Six of the seven participants cited club sports as a stressful aspect of their lives. More specifically, they cited tough team dynamics, controversial calls, and unexpected injury as situations or events that contributed to feeling overwhelmed, frustrated, or 
tense. Christina described one instance in which she found herself having to defend two of her teammates and close friends who were on the verge of being asked to leave the team for their senior year:

There were two girls in particular that we really had a tough time with our decision. Um it was particularly stressful for me because I've been very good, close friends with both of these girls and... they're both seniors and been with the team for many years and there were a number of people on the board who felt they didn't deserve a spot on the team... And I was vouching, rooting for them, trying to pull for them really hard because I felt that they've shown commitment to the team through all of these years and to not give them the opportunity to play again their senior year and cut them would just be awful. If I were in their position, I would be hurt by it... What I was getting to is, I was really stressed out because these were both close friends of mine and it would have put me in an awkward situation if they were to be cut because I'm close with them, so, I definitely would have heard some stuff. The position I was in put me under some stress. (Christina)

Julie also expressed some team-related tensions; in particular, she shared some of the details of the somewhat problematic dynamic between some of her teammates and their male coach:

It gets pretty cliquey, like girls tease one another and exclude other people from the group and our coach can't stand like the cattiness when girls just want to be like exclusive in their own group. So there was a group of three girls... and they were kind of like creating some drama, coming late to practice, show up late to 
the bus... because they didn't have respect for him. And so he, not thinking it through, approached them... kind of like not very nicely, not the way to approach someone to get them to do something, so they were like "we're quitting"... so the officers had to have a meeting with the three of them and the coaching staff, then they took it to the club sports board, then it ended up [fizzling] out, they stayed on the team, they learned a lot from our coach, it was hard and a lot of pressure because they were three of our better players. (Julie)

Julie also elaborated on a specific in-competition situation in which she had to react to a questionable call from the referee, keeping her own composure and monitoring the poise of her peers at the same time:

You can only have three yellow cards in a game and it was like the last few minutes of the game and it was a questionable third yellow card and we got called, so we had to play a man down, so going to try to communicate with the referee so like appealing the card, it was really difficulty to keep the girls calm, keep the coach calm... it was such in the heat of the moment, our playoff game was going to get us to nationals, so it was really stressful to talk to the referee but keep everyone else calm... everyone was pretty upset but we did get the call, it kept on us, but we had to communicate that the best way to deal was to stay calm. (Julie)

Brynn described in detail her experience with physical injury during the season. She had to undergo a surgical procedure and months of rehabilitation, which left her feeling frustrated and anxious: 
It was just, I couldn't do the things I used to be able to do like I'd be walking and all of a sudden my leg would give out, for a couple weeks I couldn't go up the stairs so that was a pretty big thing because I couldn't workout out... then I was waiting to get surgery, then I got surgery and it was ten times worse and had to start all over again. So just the healing process has been a big stress because the little things that happen usually my way to feel better is to go to the rec [recreation center] and be on the rowing machine or the treadmill for an hour and I couldn't do that anymore. So little things affect me more... One of my biggest fears is still probably losing my spot on the team... will I be a different athlete, will I have different strengths? Um, I've always been like one of the tougher girls on the team and so now after my injury will I be timid? (Brynn)

Lauren, on the other hand, was playing a 'waiting game' at the time of her interview; she had been advised to stop wearing contacts until her eyes had completely healed from irritation or infection. This meant that Lauren's typical physical activity regimen would have to change and decrease. As such, she was not pleased with the situation, and her perceived stress level was seemingly compounded by the fact that she had recently been elected as the club President: Like right now I'm stressed because I can't wear contacts for another month. So it's just like I can't work out... working out in glasses is nauseating because your vision comes in and out, so it's kind of like, there's stress, can't do anything... like I work out every day, and for the past two weeks I haven't because I can't... and it was the end of our season, so that was kind of stressful to like sit on the bench during games because I've never sat, I don't sit, I'm one of those people who puts in the effort and coach puts me in because I'll do what he asks, and then, 
just I was very frustrated and then there was a lot of stress I just became the President... and so I was trying to organize that... this sounds awful but like I have never sat for our games in a year and a half, I've played a full game every time... [but recently] I was sitting on a bench not doing anything and it makes you question your role on the field. (Lauren)

Social stressors. Six participants cited certain social situations involving roommates, family members, friends, or significant others as stressful. For example, Courtney and one of her roommates did not get along when they first moved in together, and their inability to initially take the other's perspective on sharing personal space resulted in what she described to be an awkward living arrangement:

Well my roommate situation was not the best... we couldn't get along together because of um I guess just how we lived, how we lived in the house, messes and stuff like that. We were constantly fighting and trying to figure out how to live with each other. (Courtney)

For Bethany and Lauren, who also described social stressors during their respective interviews, family dynamics and health status were most prominent. Bethany expressed her dissatisfaction with the differential treatment of siblings by her mother and step-father:

It just is kind of stressful when I talk to my mom and I can hear about what she lets my siblings do that I was never allowed to do when I was back home... she'll sometimes try to tell me what to do... she'll give me advice that I don't really like. (Bethany) 
Lauren expressed her level of stress to be particularly high during the previous year's final exam week, at which time she was trying to study in addition to dealing with the news that her father had been hospitalized:

Last year my dad was hospitalized for a couple of weeks, so dealing with that was... extremely stressful because it was around finals time. (Lauren)

For Katherine, fighting with her boyfriend was a source of stress, particularly when she does not 'let it go' and instead plays the argument over repeatedly in her mind:

Me and my boyfriend getting into a fight and it's all very stressful and everyone's angry and I'm on my way out... and re-playing it over and over and just getting more and more mad and more upset and frustrated. (Katherine)

Lastly, Christina described one of her most palpable social stressors to be a complicated romantic relationship with a partner who was experiencing physical pain as a result of an injury during the months that they dated and subsequently separated:

So that was stressful to know that [my boyfriend] he's going through some pain and that I couldn't be there with him [back at home] to help him cope through that [pain], that was stressful and upsetting for myself, so I told him I was like 'Well, I'm not ready to throw in the towel, I want to try the distance and give it a shot,' like, 'I don't want to give up on you,' and he was like 'OK, let's try it.' (Christina)

Transition to college. Three participants expressed a certain degree of stress related to their college lifestyle, including the initial transition to a new environment, and the various tasks and adjustments that come with being away from 'home.' Brynn explained that moving out of the house and into the college environment heightened her awareness of her increased sense of 
independence and responsibility in the absence of parents or guardians. With this new freedom and experience, she implies that she perceived herself to have matured quickly:

It's just a whole new level of responsibility and being able to balance making new friends and like your social life, school, sleeping enough, playing a sport, and if you have any other clubs going on all at the same time it's just absolutely crazy and I think it makes you grow up faster. I'm not saying anything bad about the people who stayed home and went to community college but... like [at] a big university you can't get away... it's kind of in your face. (Brynn)

For Katherine, the biggest shock was the contrasting levels of stress experiences leading up to and during college. She explains that having a fairly stress-free upbringing may not have prepared her for the many demands placed upon her following move-in; however, the new demands did prompt her to seek help and develop new strategies and routines to cope with and adapt to the many changes around her:

I didn't have an incredibly stressful life leading up to that [college transition], that was sort of the big tidal wave, but I think that was the biggest thing that sort of helped me to kick-start that [effort of] how to deal with stress... and it was also a bit of a hard adjustment because even though I'm from here I really didn't want to stay in that same high school clique... so that was stressful trying to really push myself to meet new people. (Katherine)

Julie also experienced stress upon moving away from home. Her relationship with her family is very strong, and her desire to visit her sister and her dog each weekend kept her contemplating a transfer until she made new friends and got established within her club sports team: 
I was a freshman... a real homebody, and I was afraid to come to college... I thought I might transfer home... on Sundays I'd be like, I didn't want to go back, and my one sister was at home too... so whenever I'd see my sister and my dog... I would feel upset when I'd have to go back [to campus]. (Julie)

Christina's described her most stressful college experience as extremely time-sensitive and intense. After deciding not to live downtown with her friends, she had to search for a onebedroom apartment less than one week before starting her senior year:

I was like "I'm just going to look for a place on my own"... so like four days before school started I had to find a new place by myself, I was in a panic, calling every single landlord... [after finding a place] we got there and the apartment smelled like mold, it was disgusting, it was dirty, it was dark, it was just a really stressful situation to walk into, so the next day we spent $12-13+$ hours cleaning the entire apartment, we went through 1-2 gallons of bleach, we rented a steam vac... we repainted, we completely like just redecorated everything, we had to start from scratch. (Christina)

\section{Coping Strategies}

The seven participants identified nine coping strategies that they used to deal with the stressors, or the feelings associated with the stressors, previously described. These strategies were classified into two major categories, namely problem-focused and emotion-focused coping, and are presented in this section. The researcher adhered to the definitions, descriptions, and examples provided by Nicholls and Polman's (2007) systematic review of coping in sport to determine the appropriate category for each strategy. 
Problem-focused coping strategies. Strategies defined as "problem-focused" are strategies used by an individual to change the situation or manage the stressor in order to eliminate the problem and therefore the distress (Nicholls et al., 2009). In the present study, only one problem-focused strategy was described across all seven interviews.

Seeking instrumental/informational social support. Three out of seven participants shared their use of either counseling/therapeutic services or coaching consultation during their college years. For example, Katherine sought a therapist's guidance in order to manage her anxiety, and cited her sessions with providing her many ways to relax when feeling stressed:

I've always had tons of anxiety, and so um I went to therapy and so [now] I have all of these strategies that I... use for relaxation and one of them was to get into this sort of nightly routine to unwind. (Katherine)

Similarly, Julie asked her father for sport-related guidance, given his experiences in coaching and historically helpful suggestions:

Well I did just call him or text him or whatever and he gave me suggestions and... the girls are familiar with his status as a coach and they all respect him and so I suggest the things that he suggested and we kind of worked from there. (Julie) Emotion-focused coping strategies. Emotion-focused strategies are strategies used to reduce or eliminate feelings that may result from experiencing a stressful situation, including but not limited to worry or fear. Kaiseler, Polman, and Nicholls (2009) describe one's efforts to decrease stress as "strategies used to regulate emotional arousal and distress" (p. 728). In the present study, eight emotion-focused strategies were identified across participants' interviews.

Seeking emotional social support. The most prevalent topic, or strategy, that participants discussed in relation to coping was seeking social support for emotional reasons. 
Social support of an emotion-focused nature appears to be highly valued, and provides a source of comfort, confirmation, and safety during less than ideal times. For all seven participants, and the four specifically quoted here, talking to others about various situations, persons, and events fulfills a need to be heard and to belong. For instance, Julie described her role as an officer to be very important, and thus she strived to keep team-related issues confidential. Having the ability to talk and share ideas with other officers was therefore advantageous for her coping processes:

Well one thing about being on the officer board is that everything is confidential.

So venting to the other girls that know what's happening, explain[ing] to them how you feel... talking about it and trying to get other opinions, that's the best way to deal with the stress without bottling it up. (Julie)

Additionally, Brynn described how the knowledge that one has a support system regardless of the particular circumstances might contribute to one's self-confidence:

I call my mom every day... My mom and I are like the same person. So she just tells me what she would do in a situation and it ends up being what I would do too... They just, you know, I feel like parents, you never do what they want you to do... but they love you anyway... I can make a million mistakes and knowing that someone is always going to love me is a good feeling. (Brynn)

Like Brynn, Christina values social networks on which she can depend during difficult times. However, Christina also elaborated on the fact that social support may be a somewhat gendered phenomenon, with women expected to be seeking to be comforted by the people who care about them:

It comes from being able to rely on my social networks um because anytime anyone goes through a break-up you want people to be there with you and you 
want to be surrounded by people that care about you to help you get through the process, so that helped me... Obviously it's not healthy to keep things pent up inside because at some point it's all just going to come out, so you might as well talk it out with someone, so I think just being the gender that I am I seek that comfort. (Christina)

Lauren perceived her boyfriend to be one of her most valued support persons in times of stress, in part because they spend so much time together. Lauren described his efforts to include trying to talk to her, cheer her up, or help distract her by initiating a different activity:

[My boyfriend] he'll just talk to me and make sure I'm not stressed. Like if I get a bad grade on a test, he knows I'm about to be stressed because then I have to like step up what I'm doing but he'll just make it OK by bringing me flowers or something... and if I'm in like a really bad mood, he makes dinner or something and we'll just do something else. (Lauren)

Exercising or playing a sport. Five participants stated that working out, exercising, or engaging various forms of physical activity and recreational sports were stress-relieving activities, physically and/or mentally, when dealing with one or more stressful situations. Two quotes that describe this particular coping strategy are thus presented. For Katherine, physical activity continues to contribute to her feeling happier and less anxious:

I always make sure I exercise... exercise is a huge reliever of anxiety and stress... releases all of those happy endorphins... helps me to overall have less stress... I'm happier when I exercise... when I get back I just feel overall a little bit better... I just feel more relaxed overall. (Katherine) 
Christina also recognized the psychological benefits of exercise. Moreover, she explained how physical activity and sport involvement helped to shape her body and her lifestyle in a way that will positively contribute to her future endeavors:

Well, I know I definitely worked out. Um I definitely like to go to the gym, playing lacrosse for me is just a healthy release of my stress and anger and anxiety and all of that... when I'm stressed or need to take out frustration, I go and get myself involved in some type of activity, so I pretty much decided that I wanted to lead a healthier lifestyle than what I had been doing earlier... in a sense it kind of helped me make positive changes in my life, um so coping with that stress I honestly would sometimes work out and be active twice a day, I'd go to the gym in the morning and then go to practice for two hours that same day. And it made me feel better, being active, it just releases those endorphins and um it made me feel stronger and better about myself and I was starting to lose weight in a healthy way and I was eating better, so it definitely had it's negative effects on me with the stress and sadness, but also it made me mature. (Christina)

Avoiding, ignoring, or blocking-out. An emotion-focused coping strategy expressed by five participants was the act of avoiding, ignoring, or blocking-out a particular stressor. Participants described instances in which they needed to get away, either literally or figuratively. For example, Courtney used television as a way to escape from the "real world" for a while: When I get a little too stressed, I know this is not good, but I would kind of avoid the situation, I would just kind of step back and close myself off... I've been really fond of just sitting in my room watching Grey's Anatomy all day. (Courtney) 
Bethany made, and continues to make, the decision to stay away from home - a place that represents tension and frustration for her given the family's current dynamics, specifically due to her step-father's preferential treatment of other siblings:

Well I don't go home very often... [it's a] cold atmosphere between us... I just

kind of ignore it, I'm used to it now. (Bethany)

Christina and Julie described other methods of avoidance or blocking in order to cope with perceived stressors. Christina engages in various forms of exercise to 'get away' from general stress:

Just being active, running, just getting out there and it's kind of like an escape, I just kind of forget about everything else that's going on and focus on [my sport] or going on a run or weightlifting or taking up an aerobics class or something. (Christina)

Julie described making a consistent, conscious effort to stay away from social media when attempting to focus on her homework or studying:

Probably to deal with it, I would block everything else out in my life, turn off my cell phone, put down Facebook and Twitter, get myself in the zone so I didn't have any other stressors happening in my life socially or whatever so I could focus on one thing... but um just turn down the music, turn off the phone, get it going, that's the best strategy. (Julie)

Sleeping or resting. The topic of sleep, rest, or taking a nap was discussed during three interviews. While sleep does not solve any problems, in some cases, participants credited sleep with lowering their irritability or worry, giving them time to relax, and/or providing them with an 
alternative to being over-stressed in the first place. For instance, Bethany described the importance of getting rest to help clear one's head and to pass time:

Another way that I deal with stress and that's taking a nap, and it's usually relationship stress... if I'm really stressed over something so that it makes it that I can't study and I can't focus on anything and so if I just go and take a nap and wake up, I'm better... it just helps with my mind and not thinking about things as much. Makes time pass by quicker so that if I'm waiting for a certain time it helps pass time. (Bethany)

For Christina, sufficient sleep was related to an increased likelihood of making sound decisions across various situations in which she may have found herself:

I'm the type of person where I need eight hours of sleep I really can't function on four... so I think if I'm well-rested, I can probably cope better, whereas if I'm sleep-deprived, I may make rash decisions. (Christina)

Interacting with animals or pets. Three participants expressed the fact that animals and pets play a major role in stress management. For example, Bethany described the sense of comfort that being with her dog provided, as well as her ability to use him as an excuse for small study breaks:

Having a dog there is like support... the companionship, but it'll help me take breaks [from studying], too. (Bethany)

Similar to Bethany, Brynn perceived her dog to be a positive influence in her life, particularly when it came to increasing feelings of love and belonging:

My big stress reliever is my dog, he's a chocolate lab... just having a pet, I don't know, to me is just a great feeling, coming home and having something jump all 
over you like 'I missed you so much even though you yelled at me because I peed this morning.' (Brynn)

Although dogs were most commonly discussed in interviews, other animals and general references to being in/around nature were also shared. For example, Katherine expressed her affinity for horses and interacting with them as a way to deal with stress:

Horses have always been a huge part of my life, so going out to the barn, working with the young horses, training, um was a huge de-stressor... horses are my destress. (Katherine)

Eating food. Two out of seven participants mentioned the consumption of food as a source of comfort during stressful situations, with an emphasis on making less-healthy choices in troubled times. For Lauren, ice cream helped her to 'cool down' from a frustrating and stressful experience:

'I'm going to be livid,' so just be like 'have some ice cream' (Lauren).

Christina explained that when she experiences stress, she sometimes consumes foods that might have otherwise been avoided due to lack of nutritional content:

Sometimes when I'm stressed... I try not to eat unhealthy stuff but I don't know, sometimes... yeah... It's not like I do it all the time, sometimes it's just like if I'm stressed... instead of grabbing an apple I'll eat a chocolate chip cookie instead. But I don't know where that comes from. Maybe that is also from being a woman? I think, I mean I've heard, that um when women snack they usually crave salty and sweet things, more carbohydrates and fatty stuff, whereas men prefer lean meats. So that's why I think women gain weight faster for the most part, I'm not really an expert, but I've heard. (Christina) 
Breathing or practicing mindfulness. As a result of her consultations with a therapist, one participant described her breathing technique and explained how she practices mindfulness to reduce her perceived level of stress in a given scenario:

My breathing technique is in through the nose and out through the mouth... I do that on a regular basis... it can make a huge difference... on top of that, being mindful, again something therapy taught me... I have little blue stickers that I put at different places in the house and that helps remind me to be mindful and to breathe... I can mentally remind myself, too. (Katherine)

Prayer. For one participant, prayer served as a way to cope with stress on a deeply personal, emotional level. Lauren explained how her faith helped her through a past family issue and was presently helping her to make sense of one or more stressful situations:

I pray all the time about school, relationships in my life; I mean, I cannot thank God enough... He's why any of us can sit here...last year when that was all happening, all you could do was pray, go to church, talk to my mom, talk to my best friend, make sure like everything was balanced... And when there's ever stress in my life that's what I do, I pray-- it's your little alone time with God. (Lauren)

\section{Discussion}

In this study, the researcher sought to identify the stressors that female collegiate club sport peer leaders experience and to understand the ways in which they attempt to deal with their stress. A collection of perceived stressors and coping strategies emerged from the interviews conducted with the participants. From the completed transcripts, major themes (or categories) were identified and described, and then supported with appropriate quotes. Overall, participants 
described their experiences with academic stressors, sport-related stressors, social stressors, and the transition to college.

Participants also shared with the researcher nine distinct coping strategies that they used when experiencing stress. The major strategies reported were sorted into problem-focused or emotion-focused categories, based on whether participants used a given strategy to change a stressful situation or to deal with their emotional response to that situation (Hammerstein \& Burton, 2004; Kaiseler et al., 2009; Nicholls \& Polman, 2007). The single problem-focused strategy mentioned across interviews was seeking instrumental/informational social support. Participants also described eight emotion-focused coping strategies: (a) seeking emotional social support; (b) exercising or playing a sport; (c) avoiding, ignoring, or blocking-out; (d) sleeping or resting; (e) interacting with animals or pets; (f) eating food; (g) breathing or practicing mindfulness; and (h) prayer. In the following paragraphs, the major findings from this study will be explored, and commentary on the implications will be offered.

The major stressors identified by participants were academic stressors, sport-related stressors, social stressors, and the transition to college. These stressors are relatively consistent with the literature on college student stress (e.g., Robotham, 2008; Ross et al., 1999), which suggests that students are experiencing several changes and adaptations during their years of undergraduate study. Some of these stressors may be interpreted as acute stressors (i.e., life events), such as parental divorce (e.g., Compas, Connor-Smith, Saltzman, Thomsen, \& Wadsworth, 2001), while others may be more chronic stressors (i.e., daily hassles), such as financial difficulties (e.g., Ross et al., 1999). This may be true for participants in the present study. 
Each of the four categories of stressors described by participants is supported in the existing literature on stress and coping. For instance, Mellalieu, Neil, Hanton, and Fletcher (2009) interviewed a sample of elite and non-elite athletes $(N=12)$ with an average age of 23 years about the performance and organizational-related demands that they experienced when preparing for athletic competition. From the interviews, several sources of demands within these two larger categories emerged, including injury, expectations, roles in the sport organization, and the sport's climate. Many of these sources are evident in the quotes presented in the results section. For example, Brynn discussed her experience with injury, and Christina described her conflicting feelings about being both a leader and a friend to three teammates who at one point considered quitting the team.

Similar to the sport-related stressors described, social stressors can take many different forms across individuals. Brougham, Zail, Mendoza, and Miller (2009) found that the women in their sample of undergraduate students $(N=166)$ reported increased levels of stress from social relationships (e.g., break-ups, difficulties with roommates) in comparison to male participants. Dill and Henley (1998) compared the stressors identified by traditional and non-traditional college students $(N=94)$ via the Adolescent Previewed Events Scale (APES; Compas, Davis, Forsyth, \& Wagner, 1987). The researchers reported significant differences between these two groups in many categories, including peer and social relations. Specifically, traditional students indicated that the life events related to social activities had increased impact on them (Dill \& Henley). Social events may be increasingly important to first year students, whom are regularly seeking to establish new friendships and personal mentors. The first year of college has been characterized as one with the potential for increased stress due to students" "heightened 
vulnerability" during this time of change (Compas, Wagner, Slavin, \& Vannatta, 1986, p. 242), and the number of new encounters they may experience.

Given the many changes that occur when students move away from home, and the emphasis placed on the first-year experience by participants in the present study, the transition to college was identified as a category of its own. Moving away from their families, friends, and homes, and establishing new routines for sleeping, eating, studying, and socializing can be quite chaotic for first-year students (Compas et al., 1986). For one participant in this study, the need to make changes was "kind of in your face," and therefore Brynn may have appraised her adjustment as compulsory rather than optional. Additionally, Katherine described her first year as an opportunity to step out of her comfort zone and connect with new people. Clearly, the impacts of such changes have stuck with these women, who were farther into their college careers when interviewed. Their ability to recall and describe this specific time in their lives suggests the importance that it had on their friendships, academic majors, or identity development.

In addition to the many social components of college life, and in particular the first year experience, students may face academic stressors during their undergraduate years. This trend can also continue beyond the first year, as students may observe increased workloads as they get closer to graduation. In support of the findings in the present study, for instance, Ross et al. (1999) reported that $73 \%$ of students in their sample $(N=100)$ cited 'increased class workload' as an academic stressor. This daily hassle could contribute to feeling overwhelmed at times, particularly when combined with social or sport-related stressors, or multiple academic stressors such as excessive homework and tests (e.g., Archer \& Lamnin, 1985; Kohn \& Frazer, 1986). For instance, Kohn and Frazer asked a sample of college students $(N=202)$ to generate a list of 
academic stressors, and found that examinations, final grades, and term papers were among the most stressful self-reported events. Such results indicate that students appraise certain situations in the classroom as particularly stressful, and therefore may need to identify and use effective coping strategies. This may be especially true in the present study, given that all seven participants described exams, grades, or other academic demands as stressful at some point in their college experiences.

The coping strategies explored in the present study included both problem-focused and emotion-focused strategies. It should be noted that, in contrast to the limited number of problem-focused strategies that emerged across interviews, several of the strategies that participants described could be classified as emotion-focused. Based on typological analyses of the coping strategies described, participants reported using eight times more emotion-focused strategies than problem-focused strategies. This disparity may be representative of gender differences in coping. Researchers (e.g., Crocker \& Graham, 1995; Endler \& Parker, 1990; Hammerstein \& Burton, 2004) have discussed women's use of emotion-focused coping strategies when dealing with stressful situations, highlighting what may be socially-constructed, behavioral responses to situations that occur in our environs. For instance, it is widely acknowledged that men tend to want to "fix" things, whereas women want to talk about how they "feel." Emotion-focused strategies underscore this need or desire to process (or in some cases avoid processing) one's reaction to a stressful situation rather than to address the situation directly.

In their study of college students' $(N=166)$ perceived stressors and coping strategies, Brougham et al. (2009) examined sex differences between men and women. They found that the women in their sample reported greater use of emotion-focused coping strategies. More 
specifically, the women reported using strategies such as denial, seeking emotional support, and expressing their feelings (Brougham et al.). Pilar's (2004) exploration of stress and coping in a larger sample of men and women $(N=2,816)$ underscores these findings. The researcher reported that, overall, women scored significantly higher in chronic stress and daily hassles than did men; additionally, women scored higher on measures of emotional and avoidance coping styles, in comparison to men (Pilar). These results support the prevalence of emotion-focused coping strategies described by the young women in the present study.

In fitting with the number of emotion-focused coping strategies across participants, seeking social support was the most commonly described strategy. The strategy of seeking social support is an interesting strategy in that it can be categorized into either problem-focused on emotion-focused coping based on the primary intention of the seeker. To elaborate, if one seeks social support "for instrumental reasons" so as to gather more information about a situation and/or information about how to change it, this would likely be classified as a problem-focused coping strategy; the intention is to gather information and/or resources for the individual to use to directly influence the stressor (Carver, Scheier, \& Weintraub, 1989). On the other hand, if one seeks social support for emotional reasons, then this strategy is more appropriately classified as an emotion-focused strategy (Carver et al.). For example, when an athlete seeks the comfort of her friend's embrace after missing her penalty kick, she is looking for understanding, sympathy, or reassurance, all of which are tied to the emotional response to a particular situation.

In this study, social support was sought for both instrumental/informational and emotional reasons; however, only three participants sought social support in a manner capable of being classified as problem-focused. For all other participants, family members, friends, coaches, or romantic partners served as refuges. During times of perceived stress, the 
aforementioned persons provided a sense of security, love, encouragement, or empathy. As Chao (2012) wrote on college student stress, "positive social support is as essential [to students] as good soil is to plants" (p. 5). The researcher goes on to describe somewhat of a 'domino' effect, explaining that decreased social support correlates with lower stress management, and insufficient or dysfunctional coping tactics correlate with feelings of unresolved stress (Chao). Therefore, social support can serve as a vital resource capable of buffering one's susceptibility to stress and helping students to discover other ways of coping.

Aside from seeking either instrumental/informational or emotional social support, participants described seven other coping strategies in the present study. These strategies included (a) exercising or playing a sport; (b) avoiding, ignoring, or blocking-out; (c) sleeping or resting; (d) interacting with animals or pets; (e) eating food; (f) breathing or practicing mindfulness; and (g) prayer. To address the first of these strategies, exercise as coping has been explored in the literature (e.g., Rostad \& Long, 1996), with findings that support the integration of exercise into one's lifestyle. Aerobic exercise, in particular, may be correlated with decreased levels of self-reported anxiety (e.g., DiLorenzo et al., 1999). In accordance with another coping strategy described by three participants, Jennings (1997) has suggested that owning a pet is one way to help promote physical activity, which in turn could decrease anxiety or serve as a buffer against stress (Tucker, Cole, \& Friedman, 1986).

Interacting with a pet or animal as a coping strategy has also been an area of investigation for some researchers. According to Zilcha-Mano, Mikulincer, and Shaver (2011), spending time with pets has the potential to meet several basic needs. For instance, the attachment, or bond, created between owner and animal may fulfill feelings of closeness and enjoyment on several 
occasions. Additionally, pets may give their owners "a safe haven and constitute a source of support, comfort, and relief in times of need" (Zilcha-Mano et al., 2011, p. 543).

Also during times of stress, individuals may avoid (or disengage from) a stressor by engaging in other activities, such as watching TV or going out for ice cream. These activities can be explained as behavioral responses to stressors that are perceived to be threatening in some way (e.g., Herman-Stahl, Stemmler, \& Petersen, 1995). Thus, in the cases described in the present study, Courtney, Bethany, Christina, and Julie may have felt that they did not have the resources to handle their respective stressors at that time, and resorted to involving themselves in other activities. One activity, or more appropriately lack thereof, might be sleeping. In the present study, three participants used sleep, or rest, to get away from their stressors or to allow time to pass. Carver et al. (1989) explained that individuals may choose to disengage from a stressful situation by taking their minds elsewhere (i.e., escapism). One form of disengagement (i.e., mental disengagement) occurs when an individual uses sleep as a way to separate from a stressor, and this disengagement is typically used when a poor coping outcome is expected (Carver et al., 1989).

Another activity that may relate to behavioral disengagement is eating food in times of perceived stress. Two participants in the present study cited the consumption of food as a behavior used to get away from and stop thinking about stress, or a way to have stress manifest itself in the body. The stress-eating relationship has been investigated empirically (e.g., Grunberg \& Straub, 1992) and produced interesting findings. The literature suggests that, in general, stress may decrease one's appetite or caloric intake. However, researchers have shown that the interaction is a bit more complex (e.g., Rutledge \& Linden, 1998), as when individuals are categorized as restrained eaters (eaters who are body-image conscious and watch their caloric 
intake) and unrestrained eaters (eaters who are less body-image conscious and do not track their calories).

For instance, Rutledge and Linden (1998) reported that measures of physiological arousal related to reduced food consumption among the unrestricted eaters, while impaired physiological recovery related to increased food consumption for restrained eaters who were experiencing distress. Given the fact that athletes use their bodies to perform, they may be more likely to pay attention to what they eat, thus leading to the possibility of identifying as restrained eaters. The field of sports nutrition emphasizes the relationship between good nutrition and performance (e.g., Jeukendrup \& Gleeson, 2010) and it is reasonable to expect that club sport athletes, like elite youth and college varsity athletes, are aware of such concepts. In the present study, Lauren and Christina mentioned eating food as a way to cope with stress. Christina's discussion of stress-related eating appears to apply to Rutledge and Linden's findings, and the researchers would likely describe her as a 'restrained eater' due to her self-reported awareness of healthy foods. However, this label may not be upheld when Christina experiences unusually high levels of perceived stress. In such situations, her behaviors can change; she indulges in sweet or highfat foods, and thus fits the 'unrestrained eater' description. Although Lauren's scenario is a bit vaguer, it is reasonable to hypothesize that going out for ice cream is qualitatively different than soothing oneself by crunching on a carrot. The possibility of impaired recovery may become an issue if such behavior persists.

Just as athletes may have increased awareness about the importance of nutrition, they may also be cognizant of the value of self-control, meditation, or other similar mental skills related to athletic performance. In the present study, the strategy of breathing and mindfulness emerged from Katherine's interview. Emotional control strategies, such as arousal control, 
visualization, and deep breathing have been explored in the literature (e.g., Gould, Eklund, \& Jackson, 1993; Poczwardowski \& Conroy, 2002). In a study conducted with minority medical students $(N=64)$, Paul, Elam, and Verhulst (2007) developed and implemented a Deep Breathing Meditation protocol and collected pre-, post- and follow-up data on these students during their time in school. Overall, the researchers stated that participants reported decreases in nervousness, self-doubt, and concentration loss, among other outcomes (Paul et al.). Such outcomes can certainly be important for effective coping and stress management in medical settings, as well as being applicable to other performance domains, including athletics and leadership roles. Although Paul et al.'s sample consisted of slightly older participants in a field different from athletics, the protocol could still prove to be useful for young adult athletes experiencing stress, especially because body awareness and arousal regulation are important aspects of sport performance (e.g., Strean \& Strozzi-Heckler, 2009; Zaichkowsky \& Naylor, 2004).

The final strategy identified in this study emerged from one interview. Lauren described her faith as an important component of her daily life, and spoke to the fact that religion has played a positive role in her ability to accept or manage stress at any given time. Researchers have found that many cancer and transplant patients turn to religion as a way to cope with their diagnoses, and that doing so can lead to active coping strategies and increased adjustment (e.g., Tix, \& Frasier, 1998; Weaver \& Flannelly, 2004). Although Lauren's stressful experiences are not necessarily analogous to cancer or transplant patients' experiences, the overall implications may be somewhat comparable. Lauren's perceived stress may be buffered by or decreased as a result of her unwavering belief in a higher power and locus of control. For instance, Pargament et al. (1990) have suggested that the belief in a just, benevolent God; involvement in religious 
rituals; and the experience of God as a source of support in the coping process are associated with positive outcomes when dealing with negative life events. These events could include an athletic injury or a cancer diagnosis, among others. Indeed, Lauren's interview revealed the extent to which she views God as an ever-present life partner on whom she can depend to find meaning or comfort.

The aforementioned strategies described may not be entirely comprehensive given the time allotted for each interview, however they represent the diversity of coping strategies that maybe employed by individuals across various stressful situations. The literature on coping strategies is plentiful (e.g., Nicholls \& Polman, 2007) and therefore researchers have stated that the increasing number and types of strategies identified could warrant more categories and classifications than the two used in the present study (e.g., Anshel, 1996; Kowalski \& Crocker, 2001). Well-respected stress and coping researcher, Richard Lazarus, once wrote that "the theory of coping as a process emphasizes that there are at least two major functions of coping" (Lazarus, 1998, p. 374), and thus even one of the foremost experts has acknowledged the potential for new growth and discovery across populations.

Taking a closer look at the emotion-focused strategies employed by participants, it becomes evident that some of these behaviors may have been acquired via observation, modeling, and reinforcement (Bandura, 1971). Bandura's social learning theory suggests that we, as social beings, will observe, learn, and reproduce certain behaviors that are consistent with those whom we view as models, and those behaviors that have been positively reinforced in our household, peer group, or larger culture. For instance, Brynn discussed her and her mother's congruence on several issues, which could imply that she has adopted ways of thinking and appraising specific situations from watching and speaking with her mother over time. 
Additionally, Lauren described her boyfriend's efforts to pull her attention away from a bad grade and onto something else, such as receiving flowers or doing an unrelated activity together as a couple. For both Brynn and Lauren, the reinforcement from others and exposure to certain coping behaviors could influence their decisions related to self-soothing and handling problems.

Given the age range of participants in the present study, it is reasonable to hypothesize that gender-specific behaviors, and thus coping strategies, remain prominent throughout the college years. During these pivotal years, students transition out of adolescence and into young adulthood, simultaneously navigating several transitions in their friendships, peer groups, interests, and identity (e.g., Medalie, 1981). Thus males and females may continue to act in a manner most socially acceptable or commonly reinforced so as to fit in. College students may also cling to what is familiar and what has worked in the past now that they find themselves in a different academic and social environment that requires major adjustment.

Furthermore, following the hypothesis that certain coping strategies are modeled and reinforced over time, there exists the possibility that some strategies are a perceived outgrowth of one's gender. As Christina states, "maybe [eating unhealthy foods when stressed] is also from being a woman?" It is interesting that Christina uses her gender to explain her coping behavior, especially considering that the desire to consume 'comfort food' on the whole may exist crossculturally. However, Christina's assertion that a chocolate chip cookie soothes her, in a way that steak does not, may have some merit, as there is evidence in the literature to suggest that gender may account for the consumption of specific comfort foods during times of stress (e.g., Wansink, Cheney, \& Chan, 2003). In summary, Christina's strategy of consuming food when feeling stressed, as well as other strategies described in this section, may be influenced by gender, or 
possibly dictated by gender-constructed behaviors that young girls observe during their childhood and adolescent years.

\section{Limitations}

Despite the results of the present study, it must be mentioned that these findings should be interpreted with caution. This study has several limitations that should be noted by scholars and practitioners. First, the researcher utilized convenience sampling with female participants limited to a single university, thus limiting the generalizability and extrapolation of the study's findings to club sport athletes as a whole. It could be the case that the experiences of this particular group of athletes are distinct from others at different universities. Second, the social desirability and honesty of responses are two factors to consider; participants may have responded to questions in a socially desirable manner instead of truthfully and accurately. It may be that participants wanted to please the researcher during interviews, or make themselves be seen in a more positive light when completing the demographic sheet (e.g., how many hours they actually spend training per week). Third, the self-nomination of peer leaders could be biased in many ways based on social factors and personal motives. For example, an athlete may have been inclined to nominate a close friend on the team if she feels that she will need to share her nominee's name with others. This could be the case given that the researcher often met with teams before or during practice, when athletes are socializing with one another. Fourth, a selfreport bias may have prevented participants from sharing any negative coping styles, such as drinking alcohol, smoking, or engaging in other illegal or high-risk behaviors. Fifth, the semistructured interview guide may have prompted participants to describe behaviors associated with active coping, given the emphasis on how they "deal with" perceived stressful situations. Lastly, not all interviews were conducted in person. The interviews conducted via phone were shorter in 
length, and did not allow the researcher to observe body language and capitalize on any nonverbal cues. Increased attention to interview standardization in future studies is recommended.

\section{Practical Applications and Future Research}

This study has implications for scholars, practitioners, athletes, coaches, and support personnel. By using a qualitative approach to explore the study's main purpose, the researcher was able to bring to light rich data that exposes the multiple stressors experienced, and coping strategies utilized, by peer leaders competing at the club level of collegiate athletics.

Researchers (e.g. Miles \& Huberman, 1994; Patton, 2002) have made a strong case for the use of qualitative research, and it is assumed that the proposed study provided a new perspective to the literature given the sample and procedure. Holmes, McNeil, and Adorna (2010) asserted that "the pursuit of more qualitative studies will further expand our understanding of sports leadership and leadership in general" (p. 444). With additional research of coping in the collegiate club sport context, sport practitioners can learn to better identify, develop, and educate club sport peer leaders with respect to stress management and leadership skills.

It is hoped that from the findings of this study, combined with other research in related domains, practitioners may be better equipped to develop programs that cater to the needs and values of this unique student population. One such program that has already been established and adopted by many universities across the United States is the CHAMPS/Life Skills program. This program aims to provide student-athletes with the skills necessary to manage their time, create relationships with their communities, and improve self-care habits, among other objectives (e.g., http://www.wvusports.com/staffDirectory.cfm?type=AD2\&adCatID=12). While it is currently limited in scope, primarily reaching varsity and scholarship athletes, it has the potential to be a catalyst for other similar programs that extend to other athletic college students, such as 
club sport athletes. Many universities offer a University 101 course, and this could be one mechanism through which students learn how to identify and cope with potentially stressful situations during their undergraduate experience. Additionally, several workshops could be integrated into such courses, targeting specific sub-populations and encouraging ongoing connection with reliable support persons (e.g., peers; Dennis, Phinney, \& Chuateco, 2005).

Like all college students, club sport athletes cope with stress in other areas of their lives, including in the academic and intrapersonal domains (e.g., Chao, 2011; Medalie, 1981). The results of the present study highlight the extent to which female peer leaders participating in club sports can fall victim to the exacerbation of stress across domains. In some cases, participants indicated having the capacity to successfully compartmentalize their life stressors across roles and activities. It is possible for athletes to take this information and apply it to their own lives, whether they perceive themselves to be informal or formal leaders on their teams. Additionally, coaches and support staff affiliated with club sport athletes are encouraged to recognize and manage individual and team stressors and develop ways of dealing with them in formal and informal ways. For instance, they might solicit the advice of a sport psychology consultant during weekly meetings, or carve out practice time to address issues pertinent to their players (e.g., schoolwork, upcoming travel). It is hoped that this study incites the development of mechanisms for stress management and stress reduction across club sports teams and leads to the use of helpful resources and skilled professionals.

Additionally, the results of this study suggest that club sport participants could potentially benefit from sport psychology consultations that focus on stress management, team cohesion, and leadership development, among other sport-specific and general life skills. Although the case can certainly be made that club sport athletes are very different from varsity athletes at the 
college level, it is important to recognize that the participants in this study reported training on average approximately one-half of the time that varsity athletes would be expected to train in a given week. With this in mind, it is conceivable that with additional support, club sport athletes could elevate their levels of athletic performance, improve their social relations, and more effectively utilize campus resources related to academic success and student well-being.

The described practical applications can help to inform future areas of research for scholars in the sport sciences, psychology, and sociology. First, it could benefit club sports participants to have handbooks specific to their needs, with listed resources for educational, psychosocial, and financial support. Contact persons listed in this handbook would likely include faculty advisors, campus facilities, the counseling center, sport psychologists or sport psychology graduate students, and local athletic trainers or physical therapists. Upon creating and distributing these handbooks, researchers can evaluate their effectiveness based on selfreported usage, as well as the number of referrals made each year as a result of their distribution across teams. Additionally, researchers should seek to explore the ways in which coaches and other mentors can contribute to athletes' knowledge and practice of healthy, effective coping strategies. Moreover, the modeling and reinforcement of coping behaviors amongst peers may be a particularly interesting area of research. Peer mentoring may become more common in college, both inside and outside of the athletic environment, due to the fact that undergraduate students typically live, study, and socialize with one another (e.g., Milem, 1998).

\section{Closing Thoughts}

Overall, the results of the present should not be entirely surprising, given the existing literature on the wide variety of stressors reported by college students (e.g., Ross et al., 1999), the complexity of the coping process (e.g., Nicholls \& Polman, 2007), and the observed gender 
differences related to dealing with stressful situations (e.g., Crocker \& Graham, 1995;

Hammerstein \& Burton, 2004). Stress is considered to be a natural occurrence in the college years, and coping is a complex process that consists of individual experiences, appraisal, and an evaluation of one's available coping skills or resources. It can be extremely challenging to successfully compartmentalize roles, responsibilities, and stressors throughout the day and across situations and persons, especially during times of transition and uncertainty (e.g., Medalie, 1981). Thus, it is understandable that Brynn describes a sort of reverse domino effect in her interview; if she gets a good night's rest, then she can better handle situations that come her way. If we were to interpret this further, we might see that this statement reflects the impact that one stressful experience, paired with ineffective coping, can potentially have on one's attitude for the remainder of the day. Topics such as work-life balance continue to be highlighted in popular magazines and online blogs such as Forbes and Huffington Post. These articles, in combination with scholarly research and anecdotal evidence, confirm the findings of the present study. The process of identifying, interpreting, and responding to perceived stressful experiences is complex, modifiable, and multifaceted, and is particularly powerful during the college years. 


\section{References}

Andersen, M. B., \& Williams, J. M. (1988). A model of stress and athletic injury: Prediction and prevention. Journal of Sport \& Exercise Psychology, 10, 294-306.

Anshel, M. H. (1996). Coping styles among adolescent competitive athletes. Journal of Social Psychology, 136(3), 311-323.

Anshel, M. H., \& Sutarso, T. (2007). Relationships between sources of acute stress and athletes' coping style in competitive sport as a function of gender. Psychology of Sport and Exercise, 8, 1-24.

Anshel, M. H., Sutarso, T., \& Jubenville, C. (2009). Racial and gender differences on sources of acute stress and coping style among competitive athletes. The Journal of Social Psychology, 149(2), 159-177.

Archer, J., Jr., \& Lamnin, A. (1985). An investigation of personal and academic stressors on college campuses. Journal of College Student Personnel, 26(3), 210-215.

Bandura, A. (1971). Social learning theory. New York City, NY: General Learning Corporation.

Brougham, R. R., Zail, C. M., Mendoza, C. M., \& Miller, J. R. (2009). Stress, sex differences, and coping strategies among college students. Current Psychology, 28, 85-97.

Carver, C. S., \& Scheier, M. F. (1994). Situational coping and coping dispositions in a stressful transaction. Journal of Personality and Social Psychology, 66(1), 184-195.

Carver, C. S., Scheier, M. F., \& Weintraub, J. K. (1989). Assessing coping strategies: A theoretically based approach. Journal of Personality and Social Psychology, 56(2), 267283.

Chao, R. C. (2011). Managing stress and maintaining well-being: Social support, problemfocused coping, and avoidant coping. Journal of Counseling \& Development, 89, 338- 
348.

Chao, R. C. (2012). Managing perceived stress among college students: The roles of social support and dysfunctional coping. Journal of College Counseling, 15, 5-21.

Compas, B.E., Davis, G.E., Forsythe, C.J., \& Wagner, B.M. (1987). Assessment of major and daily stressful events during adolescence: The adolescent perceived events scale. Journal of Consulting and Clinical Psychology, 55(4), 534-541.

Compas, B. E., Connor-Smith, J. K., Saltzman, H., Thomsen, A. H., \& Wadsworth, M. E. (2001). Coping with stress during childhood and adolescence: Problems, progress, and potential in theory and research. Psychological Bulletin, 127(1), 87-127.

Compas, B. E., Wagner, B. M., Slavin, L. A., \& Vannatta, K. (1986). A prospective study of life events, social support, and psychological symptomatology during the transition from high school to college. American Journal of Community Psychology, 14(3), 241-257.

Creswell, J. W. (2007). Qualitative inquiry \& research design. Thousand Oaks, CA: Sage Publications.

Crocker, P. R. E., \& Graham, T. R. (1995). Coping by competitive athletes with performance stress: Gender differences and relationships with affect. The Sport Psychologist, 9(3), $325-338$.

Dennis, J. M., Phinney, J. S., \& Chuateco, L. I. (2005). The role of motivation, parental support, and peer support in the academic success of ethnic minority first-generation college students. Journal of College Student Development, 46(3), 223-236.

Denzin, N. K., \& Lincoln, Y. S. (2005). The Sage handbook of qualitative research ( ${ }^{\text {rd }}$ ed.). Thousand Oaks, CA: Sage Publications, Inc.

Dill, L. P., \& Henley, B. T. (1998). Stressors of college: A comparison of traditional and nontraditional students. The Journal of Psychology, 132(1), 25-31. 
DiLorenzo, T. M., Bargman, E. P. Stucky-Ropp, R., Brassington, G. S., Frensch, P. A., \& LaFontaine, T. (1999). Long-term effects of aerobic exercise on psychological outcomes. Preventative Medicine, 28(1), 75-85.

Dupuis, M., Bloom, G., \& Loughead, T. (2006). Team captains’ perceptions of athlete leadership. Journal of Sport Behavior, 29, 60-78.

Endler, N. S., \& Parker, J. D. A. (1990). Multidimensional assessment of coping: A critical evaluation. Journal of Personality and Social Psychology, 58, 844-854.

Fischer, C. T. (2009). Bracketing in qualitative research: Conceptual and practical matters. Psychotherapy Research, 19(4-5), 583-590.

Folkman, S., Lazarus, R. S., Pimley, S., \& Novacek, J. (1987). Age differences in stress and coping processes. Psychology of Aging, 2(2), 171-184.

Gaudreau, P., \& Blondin, J. P. (2002). Development of a questionnaire for the assessment of coping employed by athletes in competitive sport settings. Psychology of Sport and Exercise, 3, 1-34.

Gould, D., \& Carson, S. (2008). Life skills development through sport: Current status and future directions. International Review of Sport and Exercise Psychology, 1(1), 58-78.

Gould, D., Eklund, R. C., \& Jackson, S. A. (1993). Coping strategies used by U.S. Olympic wrestlers. Research Quarterly for Exercise and Sport, 64(1), 83-93.

Gould, D., \& Voelker, D. K. (2010). Youth sport leadership development: Leveraging the sports captaincy experience. Journal of Sport Psychology in Action, 1(1), 1-14.

Grunberg, N. E., \& Straub, R. O. (1992). The role of gender and taste class in the effects of stress on eating. Health Psychology, 11(2), 97-100.

Hammermeister, J., \& Burton, D. (2004). Gender differences in coping with endurance sport 
stress: Are men from Mars and women from Venus?. Journal of Sport Behavior, 27, 148164.

Herman-Stahl, M. A., Stemmler, M., \& Petersen, A. C. (1995). Approach and avoidant coping: Implications for adolescent mental health. Journal of Youth and Adolescence, 24(6), 649665.

Holm, J. E., \& Holroyd, K. A. (1992). The Daily Hassles Scale (Revised): Does it measure stress or symptoms?. Behavioral Assessment, 14, 465-482.

Holmes, R. M., McNeil, M., \& Adorna, P. (2010). Student athletes' perception of formal and informal team leaders. Journal of Sport Behavior, 33(4), 442-465.

Humphrey, J. H., Yow, D. A. \& Bowden, W. W. (2000). Stress in college athletics: Causes, consequences, coping. Binghamton, NY: The Haworth Half-Court Press.

Jennings, L. B. (1997). Potential benefits of pet ownership in health promotion. Journal of Holistic Nursing, 15(4), 358-372.

Jeukendrup, A., \& Gleeson, M. (2010). Sport nutrition: An introduction to energy production and performance $\left(2^{\text {nd }}\right.$ ed.). Champaign, IL: Human Kinetics.

Kaiseler, M., Polman, R., \& Nicholls, A. (2009). Mental toughness, stress, stress appraisal, coping and coping effectiveness in sport. Personality and Individual Differences, 47, 728-733.

Kanner, A. D., Coyne, J. C., Schaefer, C., \& Lazarus, R. S. (1981). Comparison of two modes of stress measurement: daily hassles and uplifts versus major life events. Journal of Behavioral Medicine, 4(1), 1-39.

Kohn, J. P., \& Frazer, G. H. (1986). An academic stress scale: Identification and rated importance of academic stressors. Psychological Reports, 59, 415-426. 
Kowalski, K. C., \& Crocker, P. R. E. (2001). The development and validation of the Coping Function Questionnaire for adolescents in sport. Journal of Sport and Exercise Psychology, 23, 136-155.

Lazarus, R. S. (2000). How emotions influence performance in competitive sports. The Sport Psychologist, 14, 229-252.

Lazarus, R. S. (1998). Fifty years of the research and theory of R. S. Lazarus: An analysis of historical and perennial issues. Mahwah, NJ: Lawrence Erlbaum Associates, Inc.

Lazarus, R. S., \& Folkman, S. (1984). Stress, appraisal and coping. New York City, NY: Springer.

Lifschutz, L. (2012). Club sports: Maximizing positive outcomes and minimizing risks. Recreational Sports Journal, 36, 104-112.

Lindsey, R. R. (2012). The benefits and satisfaction of participating in campus recreational sports facilities and programs among male and female African American students: A pilot study. Recreational Sports Journal, 36, 13-24.

Lorber, J. (1994). Night to his day: The social construction of gender. In Paradoxes of Gender (pp. 13-36). Binghampton, NY: Yale University Press.

Loughead, T. M., \& Hardy. J. (2005). An examination of coach and peer leader behaviors in sport. Psychology of Sport and Exercise, 6, 303-312.

Mertens, D. M. (2005). Research and evaluation in education and psychology: Integrating diversity with quantitative, qualitative, and mixed methods $\left(2^{\text {nd }}\right.$ ed. $)$. Thousand Oaks, CA: Sage Publications, Inc.

Medalie, J. (1981). The college years as a mini-life cycle: Developmental tasks and adaptive options. Journal of American Health Association, 30, 75-90. 
Mellalieu, S. D., Neil, R., Hanton, S., \& Fletcher, D. (2009). Competition stress in sport performers: Stressors experienced in the competition environment. Journal of Sport Sciences, 27(7), 729-744.

Milem, J. F. (1998). Attitude change in college students: Examining the effect of college peer groups and faculty normative groups. The Journal of Higher Education, 69(2), 117-140.

Miles, M. B., \& Huberman, A. M. (1994). Qualitative data analysis: An expanded sourcebook. Thousand Oaks, CA: Sage Publications.

Nicholls, A., \& Polman, R. C. J. (2007). Coping in sport: A systematic review. Journal of Sport Sciences, 25, 11-31.

Nicholls, A. R., Polman, R., Morley, D., \& Taylor, N. J. (2009). Coping and coping effectiveness in relation to a competitive sport event: Pubertal status, chronological age, and gender among adolescent athletes. Journal of Sport and Exercise Psychology, 31(3), 299-317.

Nicholls, A. R., Polman, R., Levy. A. R., Taylor, J., \& Cobley, S. (2007). Stressors, coping, and coping effectiveness: Gender, type of sport, and skill differences. Journal of Sport Sciences, 25(13), 1521-1530.

Pargament, K. I., Ensing, D. S., Falgout, K., Olsen, H., Reilly, B., Van Haitsma, K., \& Warren, R. (1990). God help me: (I): Religious coping efforts as predictors of the outcomes to significant life events. American Journal of Community Psychology, 18, 793-824.

Patton, M. Q. (2002). Qualitative research \& evaluation methods ( $3^{\text {rd }}$ ed.). Thousand Oaks, CA: Sage Publications.

Paul, G., Elam, B., \& Verhulst, S. J. (2007). A longitudinal study of students' perceptions of using a deep breathing meditation to reduce testing stresses. Teaching and Learning in Medicine: An International Journal, 19(3), 287-292. 
Pennington, B. (2008, December 2). Rise of college club teams creates a whole new level of success. New York Times.

Pilar, M. M. (2004). Gender differences in stress and coping styles. Personality \& Individual Differences, 37(7), 1401-1415.

Poczwardowski, A., \& Conroy, D. E. (2002). Coping responses to failure and success among elite athletes and performing artists. Journal of Applied Sport Psychology, 14(4), 313329.

Ptacek, J. T., Smith, R. E., \& Zanas, J. (1992). Gender, appraisal, and coping: A longitudinal analysis. Journal of Personality, 60(4), 747-770.

Roberts, T., Miller, T., \& Wells, J. (Eds.). (2003). Sports clubs: A resource guide. Corvallis, OR: NIRSA.

Robotham, D. (2008). Stress among higher education students: Towards a research agenda. Higher Education, 56, 735-746.

Ross, S. E., Niebling, B. C., \& Heckert, T. M. (1999). Sources of stress among college students. College Student Journal, 33, 312-318

Rostad, F. G., \& Long, B. C. (1996). Exercise as a coping strategy for stress: A review. International Journal of Sport Psychology, 27(2), 197-222.

Rutledge, T., \& Linden, W. (1998). To eat or not to eat: Affective and physiological mechanisms in the stress-eating relationship. Journal of Behavioral Medicine, 21, 221-240.

Sarason, I. G., Johnson, J. H., \& Siegel, J. M. (1978). Assessing the impact of life changes: Development of the Life Experiences Survey. Journal of Consulting and Clinical Psychology, 46(5), 932-946.

Strean, W. B., \& Strozzi-Heckler, R. (2009). (The) body (of) knowledge: Somatic contributions 
to the practice of sport psychology. Journal of Applied Sport Psychology, 21(1), 91-98.

Tix, A. P., \& Frasier, P. A. (1998). The use of religious coping during stressful life events: Main effects, moderation, and mediation. Journal of Consulting and Clinical Psychology, 66, 411-422.

Tucker, L. A., Cole, G. E., \& Friedman, G. M. (1986). Physical fitness: A buffer against stress. Perceptual \& Motor Skills, 63, 955-961.

Voelker, D. K., Gould, D., \& Crawford, M. J. (2011). Understanding the experience of high school sports captains. The Sport Psychologist, 25, 47-66.

Wansink, B., Cheney, M. M., \& Chan, N. (2003). Exploring comfort food preferences across age and gender. Physiology \& Behavior, 79, 739-747.

Weaver, A. J., \& Flannelly, K. J. (2004). Nurses and chaplains: Spiritual partners in healing modern medicine. Spirituality \& Health, 7(4), 16.

Yi, J. P., Smith, R. E., \& Vitaliano, P. P. (2005). Stress-resilience, illness, and coping: A personfocused investigation of young women athletes. Journal of Behavioral Medicine, 28(3), 257-265.

Zaichkowsky, L. D., \& Naylor, A. H. (2004). Arousal in sport. In C. Spielberger (Ed.), Encyclopedia of Applied Psychology (pp. 155-161). Waltham, MA: Academic Press.

Zilcha-Mano, S., Mikulincer, M., \& Shaver, P. R. (2011). An attachment perspective on humanpet relationships: Conceptualization and assessment of pet attachment orientations. Journal of Research in Personality, 45(4), 345-357. 


\section{Appendix A: Demographics Survey}

Please indicate the following my placing an " $\mathrm{X}$ " next to the response that best describes you today. There are no correct or incorrect answers.

\begin{tabular}{|c|c|c|}
\hline 1. Age & & 2. Marital Status \\
\hline 18 & 19 & Single \\
\hline 20 & 21 & Married \\
\hline 22 & & Other \\
\hline
\end{tabular}

3. Year in College
Freshman
Sophomore
Junior
Senior

4. Hours of training (on average): hours per week

5. Number of years in your sport (at any level):

6. Number of years in your sport (just in college):

7. Indicate your reason(s) for choosing to participate in college club sports: Stress management Fitness/health/weight management Socialize and/or make friends Competition Other, please explain:

8. Have you ever worked with a sport psychology consultant, either individually or with a team? Yes No

9. Circle the number (1-7) that indicates the currently stress level that you experience in club sports:

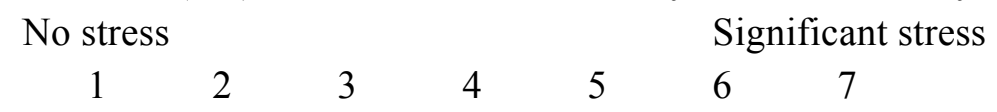

10. Do you perceive yourself to be a leader on your college club sports team? Yes No 
11. Please indicate if you have sought help from any of the following for stress-related issues:

Therapist/counselor If yes, for what period of time?

Religious leader If yes, for what period of time?

Academic mentor If yes, for what period of time?

Friend

If yes, for what period of time?

Parent or sibling

If yes, for what period of time?

Significant other

If yes, for what period of time?

Coach

If yes, for what period of time?

Peer/team leader

If yes, for what period of time? 


\section{Appendix B: Peer Leader Nomination Prompt}

Please write the name of the person on your team who serves as the team leader-either formally or informally_by representing, demonstrating, or embodying leadership. 


\section{Appendix C: Semi-Structured Interview Guide}

1. Can you describe for me how you see yourself on the team? What is your role?

2. Could you describe for me any stressful situations you've experienced during your time at this university (at WVU)?
a) In club sports?
b) Academically?
c) Socially?
d) With your family?
e) Finances?
f) Others?

3. Could you describe for me how you deal with stressful situations, such as the ones that you've previously mentioned?
a) Listen to music
b) Sleep or relax
c) Socialize or talk on the phone with friends or family
d) Surf the internet or social networking sites
e) Do something active (hike, bike, walk, exercise)
f) Other

4. How or where did you learn to cope, or deal with, stress?

5. How would you evaluate your ability to effectively cope with stress?

Note. The probes listed were used when/where necessary. 


\section{Appendix D: Cover Letter to Participants}

Dear Participant,

This letter is a request for you to take part in a research project for the researcher's Master's thesis. You will be asked to complete a brief quantitative survey of athletic experiences, as well as to describe your demographic information on a demographics sheet. Additionally, you will also be prompted to answer one open-ended question about your team. This project is being conducted by Leigh Bryant, a graduate student in the College of Physical Activity and Sport Sciences at West Virginia University (Morgantown, WV). Your participation in this project will take approximately 15 minutes. There is potential for follow-up research to take place. If the researcher contacts you, you have the choice to participate in additional research at a date and time convenient for you.

Your involvement in this project will be kept confidential. You must be 18 years of age or older to participate. I will not ask any information that allows you to be identified as a participant - other than your name, which is necessary in order to contact you via your MIX email account for potential follow-up questions. Your participation in this project is completely voluntary, and you do not need to answer any questions that you do not wish to answer. You may stop your participation at any time without penalty. Furthermore, your academic and/or athletic standing will not be affected if you decide to either not participate or withdraw from participating. West Virginia University's Institutional Review Board acknowledgment of this study is on file. You can read about the University's IRB here: http://oric.research.wvu.edu/human_subjects_research and the irb.

I hope that you will participate in this research project, as it could be very beneficial in helping sport psychology practitioners to better understand club sports athletes' coping strategies in relation to athletics and life in general. This information can subsequently be used to inform future work with club sports athletes. Should you have any questions about this letter or the research project, please feel free to contact Leigh Bryant at lbryant1@mix.wvu.edu or Dr. Damien Clement, at Damien.Clement@mail.wvu.edu. Thank you for your time.

Sincerely, Leigh Bryant 


\section{Appendix E: Extended Review of Literature}

\section{Introduction}

This chapter will consist of a review of literature, specifically highlighting research focused on the topics of stress and coping, which are directly related to the study's main purpose. This review will also explore peer leadership, given that the participants in this study were individuals whom their teammates identified as being "leaders" on their respective club sports teams. The section will begin with an introduction to stress and coping, as well as an overview of previous research and instrumentation development specific to these constructs. An overview of leadership, generally and in sport, will follow this section, and conclude with a discussion of various studies in which the researchers simultaneously address coping and leadership. The literature on stress, coping, and leadership, and the interplay of these constructs will reveal the origins of the proposed and lay the foundation for its procedure, methodology, and analyses.

\section{Defining Coping}

The ability of an individual to successfully meet a stressful situation with an appropriate behavioral response is a process that spans the spectrum of humanity. The context of sport is one area where an individual's repertoire in this respect is perhaps most readily viewed and frequently called upon across several circumstances. Coping is defined as the "cognitive, affective, and behavioral efforts to manage specific external and/or internal demands" (Crocker, Kowalski, \& Graham, 1998, p. 149). In the case of experienced individuals, such as professional and highly skilled athletes with multiple sport-specific coping resources, coping may not be an arduous, slow process (see Goyen \& Anshel, 1998). However, it can take time to learn and integrate coping resources into one's behavioral patterns, as when an inexperienced athlete finds him or herself in a new or unique situation. Two divergent approaches to coping are often 
identified in the existent body of research literature and remain prominent among explanations of the theoretical basis of the topic. These two approaches are the trait approach and the process approach (Penley, Tomaka, \& Wiebe, 2002).

The trait approach corroborates much of personality theory, which maintains the idea that individuals' personalities and behaviors are rather stable and predictable over time or situation (e.g., Buss, 1989; Deisinger, Cassisi, Whitaker, 2003). Accordingly, the trait approach is often measured in psychological research via questionnaires and interviews (Penley, Tomaka, \& Wiebe, 2002), two common measures in the social sciences. Experimental measures are not utilized with this approach given that the manipulation of internal or external variables is rarely assumed to be related to differential outcomes in regards to coping. If coping strategies are relatively fixed across time and experience, then it follows that the trait approach typically dismisses the influence of situational factors on individuals' thoughts and actions and focuses on what individuals "usually" do in response to stressors (Nicholls \& Polman, 2007, p. 11).

For example, Ptacek, Pierce, and Thompson (2006) investigated the conditions under which dispositional coping and situational coping behaviors were related to one another within a sample of first- and second-year college students $(N=93)$ and their parents. They administered the COPE (Carver et al., 1989) to students in order to assess dispositional coping, and parents also filled out this instrument via mail. Upon computing analyses and correlations between and among the reported scores, the researchers concluded that dispositional coping was upheld due to the degree of agreement between mothers' and fathers' responses, and to a lesser extent between the parents' and students' responses. The researchers cite several limitations, including the low response rate of parents within their sample as well as the fact that "coping preferences of 18- to 20-year olds may still be forming" (p. 1149). Nevertheless, the study's findings point to the 
importance of further research in this area, possibly with procedures that are not retrospective and instruments that assess coping on a daily basis (Ptacek et al.).

In contrast to the trait approach, the process approach views coping as a "dynamic and recursive process that involves interactions between a person's internal and external environments" (Nicholls \& Polman, 2007, p. 11). This approach in essence reflects the potential influence of several factors that the trait approach neglects to address. Researchers and theorists who adopt the process approach (e.g., Larsen, 2003) maintain that individuals' cognitive and behavioral efforts are constantly changing due to the fact that the appraisals may fluctuate based on factors such as time and experience. Those who endorse or provide evidence for the process approach (e.g., Poczwardowski \& Conroy, 2002) also recognize that individuals may have preferred coping strategies, but that these preferences do not imply an unwavering bias toward strategies that are ineffective in diverse circumstances. In other words, the process approach allows for an individual's ability to discern when a typical common coping strategy might not be most effective, and to instead opt to try another, alternate coping strategy. To sum up, the process approach leaves room for personal evaluation of a given situation or context, which ultimately informs one's appraisal of the circumstance and informs the coping strategy employed to deal with it.

\section{Coping and Appraisal}

Two stages of appraisal are generally identified in the literature, namely primary and secondary appraisal (Nicholls \& Polman, 2007). Primary appraisal occurs when an individual perceives a particular stressor and subsequently makes judgments as to how much it affects what is happening in the present moment. One might ask: "Is it relevant to my values, beliefs, or goals?" (Nicholls \& Polman). If so, then the individual will seek to identify whether the stressor 
poses harm or threat, or if it can be interpreted as a challenge. To elaborate, threat is typically described as any stressor that poses immediate consequences for the individual, and it often generates feelings of worry or anxiety (Anshel, 2012). Harm-loss typically refers to events that have happened in the past, such as season-ending injuries. Some elite athletes frequently interpret stressors as challenges, as they aim to control how intensely they respond to the stressful circumstances and to what extent they allow the circumstances to change their course of action (Anshel).

For example, in one study conducted by Carver and Scheier (1994), undergraduate students $(N=125)$ completed the COPE scale developed by Carver, Scheier, and Weintraub (1989) in order for the researchers to assess self-reported situational coping at select days before and after taking an exam and receiving their grades. Carver and Scheier organized the students' self-reported responses into four categories of affect by having students rate their feelings about the exam at various points on a 5-point Likert scale. Students could rate themselves as experiencing feelings that correspond to (a) threat (feeling worried, anxious, and fearful); (b) challenge (feeling eager, hopeful, and confident); (c) harm (guilty, anger, and disappointed); and (d) benefit (relieved, happy, and pleased). The threat and harm categories were considered by the authors to be "anticipatory appraisal emotions" while the other two categories — challenge and benefit — were considered "outcome appraisal emotions," especially given the time-sensitive nature of this study. In summary, primary appraisal lays the groundwork for how one will interpret a given stressor and ultimately how an individual might go about selecting and using a particular coping strategy in order to deal with it. This selection process is commonly referred to as secondary appraisal. 
Secondary appraisal has been described as a decision-making step in which individuals use their cognitive-evaluative skills to take inventory of available coping options (Lazarus, 2000; Nicholls \& Polman, 2007). An individual at this point seeks to evaluate the extent to which he or she has the necessary knowledge and skills to move forward with the present stressor, and to identify the resources that the situation requires (Lazarus \& Folkman, 1984). For example, an athlete who is verbally reprimanded for performing an illegal slide-tackle may quickly appraise the coach's reprimand as a threat to one's self-esteem (given that the athlete admires and wants to please the coach). Then, in secondary appraisal, the athlete is likely to determine if he or she has the tools necessary to combat the negative self-talk that may originate in response to this threat. The extent to which the athlete has the ability to deal with self-talk may influence his or her decision to use a specific strategy aligned with a particular type of coping.

\section{Coping Strategies}

Coping strategies are often described as being derived from, and organized within, certain categories or dimensions (Nicholls \& Polman, 2007). The two aforementioned categories, problem-focused coping and emotion-focused coping, are commonly found in the literature. Problem-focused coping occurs when an individual intends to alter the stressful situation (Nicholls \& Polman). Examples might include seeking information, planning and setting goals, assertive confrontation, awareness of cues, task-oriented coping, time management, and learning about your opponents. Other strategies discussed in the literature include active coping and suppression (Hammermeister \& Burton, 2004). In contrast, emotion-focused coping occurs when an individual deals with the emotional distress associated with a stressful situation rather than addressing the situation itself, specifically focusing on emotion-regulation (Lazarus \& Folkman, 1984). Kaiseler, Polman, and Nicholls (2009) describe emotion-focused coping 
strategies as those tactics "used to regulate emotional arousal and distress" (p. 728), often through methods such as seeking social support, wishful thinking, and relaxation or meditation (Nicholls \& Polman). Other coping strategies associated with this category include dissociation, the use of humor, positive reinterpretation, and turning to religion (Hammermeister \& Burton).

Researchers who seek to explore different patterns of coping find that a keen understanding of social support becomes imperative. This is due to the fact that a particular coping strategy may be considered problem- or emotion-focused, based on the purpose or rationale behind its use. The act of seeking social support "for instrumental reasons" would likely be a problem-focused coping strategy because the intention is to gather information and/or resources for the individual to use (Carver, Scheier, \& Weintraub, 1989, p. 269). On the other hand, seeking social support for emotional reasons is leaning more toward seeking understanding, sympathy, and reassurance, and would therefore fall under the category of emotion-focused coping (Carver et al.).

Researchers who investigate coping strategies and social support on the whole must be specific with their questionnaire items, interview probes, and concept mapping instructions when soliciting responses from research participants; the difference in the primary intention may dictate the direction of the research and clarify for the researcher how to measure social support as a construct (Carver, Scheier, \& Weintraub, 1989). For instance, Carver et al. found that social support could have good or bad "overtones" depending on whether it was associated with active coping and planning or denial and disengagement, given that they found the former two strategies to be inversely associated with the latter two strategies. Such a finding might be evidence for the importance of clarifying the purpose of seeking social support — specifically, deeming it to be a problem-focused or emotion-focused strategy. 
Several other categories of coping strategies have been identified and described in the research literature, including avoidance coping, transcendental coping, approach coping, and appraisal-focused coping (Nicholls \& Polman, 2007; Nicholls et al., 2007; Yoo, 2001). Avoidance coping may be described as the behavioral and psychological attempts to either distance oneself or otherwise disengage oneself from stressors (Nicholls \& Polman, 2007). Common strategies related to avoidance coping may include blocking, thought stopping, behavioral avoidance, denial, and doing nothing (e.g., Nicholls et al.; Kaiseler et al., 2009). Transcendental coping occurs when an individual strives to eliminate mundane desires and expectations via self-acceptance (e.g., Yoo). Unlike avoidance coping, the transcendental approach does not involve any sort of denial or attempts to avoid stress.

Approach coping is often described as occurring when an individual confronts the source of the stressor and actively works to reduce its intensity or effects (Nicholls \& Polman, 2007). Approach coping may be considered a sub-category of or analogous to problem-focused coping, as individuals utilizing this approach work to remedy the situation rather than to react emotionally to or run away from the initial source. Lastly, appraisal coping occurs when an individual attempts to re-evaluate a certain stressor in an effort to reduce its overall importance and/or influence (Nicholls \& Polman). As implied in its name, appraisal coping is all about what and how the individual thinks. This type of coping closely parallels the work of Albert Ellis because the "thoughts cause feelings" paradigm of rational emotive behavioral therapy focuses on re-appraising certain thoughts and situations so as to dispute and decrease irrational and unhelpful self-talk (Walen, DiGuiseppe, \& Dryden, 1992). Taken together, the described categories of coping strategies can be useful in terms of identifying the specific behaviors 
involved in the coping process and understanding the ways that individuals might face, appraise, and deal with various perceived stressors across time and experience.

\section{Coping with Stress: College Students}

One unique experience for many young adults is the college experience. College students are an interesting population in which to explore stress and coping due to the multiplicity of intrapersonal, interpersonal, and professional transitions and activities that commonly occur in the college years (e.g., Medalie, 1981). For example, Medalie has described the first year of college as a time when we might expect students to disengage from the nuclear family unit and consequently engage more fully with their peers as they navigate their personal beliefs, values, and aspirations. Such experiences can certainly be exciting, but there is also likely to be some confusion, insecurity, or anxiety with respect to making the "leap" to college and declaring one's independence from the persons with which students were raised. Perceived stressors may come from the transition to, time in, and exit from college for a number of reasons. Stress may also originate from the numerous demands which students are likely to be attempting to manage simultaneously during the college years.

These demands exist within several facets of life, including one's social interests, academic pursuits, financial status, romantic relationships, athletic involvement, and the jobhunting process. Bland, Melton, Welle, and Bigham (2012), who conducted a study of millennial college students' $(N=246)$ lifestyle habits and coping strategies that might relate to high or low levels of stress tolerance, have noted that even contemporary technological advancements may be causing increased stress, citing text messages and email as potential stressors for some young adults. Additionally, the researchers identify the "active parent" or "helicopter" parent as a source of social or familial stress, and the expectations for high 
achievement to weigh heavily on some students' minds (p. 364). Using a compilation of several adapted instruments related to stress in college students, including a revised version of the Stress Tolerance Questionnaire (Welle \& Graf, 2011) and several items from self-report life event and daily hassle surveys, the researchers assessed students' levels of stress tolerance by splitting the sample into "low" and "high" groups based on total stress tolerance scores. They then ran descriptive statistics and chi-square analyses to explore the most common stressors and coping strategies used by millennial college students as well as any group differences between the low and high groupings.

Bland et al. (2012) showed that parental expectations, beginning college, choosing a major, relationship problems, tests, text messaging, lack of sleep, time management, and body image were life events and daily hassles reported by over half of their sample. Among the most common coping mechanisms were listening to music (95.1\%), sleeping (93.4\%), socializing (93.4\%), surfing the Internet (88.1\%), calling a friend $(84.8 \%)$, and exercising $(81.4 \%)$. Additionally, the researchers reported that, among the 29 coping mechanisms identified in their study, the low and high stress tolerance groupings used 10 of these mechanisms differently. Among the 10 mechanisms were taking study breaks, calling mom or a friend, eating, cleaning, and shopping. Although the researchers note that their restricted demographic sampling may affect the generalizability of their results to other students in different parts of the world and at different stages of the college experience, they suggest that social support may be a crucial and perhaps "protective" factor in the coping process and that the current literature on stress and coping among college students should be revised to best represent the millennial college student population (p. 373). The idea of measuring coping among incoming students and implementing 
research findings into first year experience classes may be a popular one for those institutions seeking to lower students' stress levels (Bland et al.).

\section{Measuring Coping}

Several researchers have developed instruments that assess coping behaviors. Over time, some of the instruments have been revised by researchers or used as the basis for developing new instruments. The Ways of Coping Scale (WOCS; Folkman \& Lazarus, 1988) was published in the late 1980s and underwent one subsequent revision (Carver, Scheier, \& Weintraub, 1989) by the developers. The WOCS assesses specific reactions to stressful situations with "yes" or "no" responses to each item on a multi-point measurement scale (Carver, Scheier, \& Weintraub). The instrument presupposes that responses will relate to either emotion-focused or problem-focused coping strategies (Rexrode, Petersen, \& O’Toole, 2008). Since its inception, researchers have continued to use the WOCS and to investigate its reliability, validity, and applicability across different sample populations (e.g., Edwards \& O’Neill, 1998). For instance, Edwards and O'Neill ran two sets of confirmatory factor analyses of the 66-item measure (which they called the Ways of Coping Questionnaire, or WCQ) with a sample of graduate students $(N=2,514)$ at a large American graduate business school. They concluded that the structures "yielded poor fit" (p. 975), and provided the explanation that, while some of the WCQ items are relatively specific and capable of corresponding to one coping behavior or strategy, others are relatively broad.

Shortly following Edwards and O’Neill's (1998) publication, a pair of researchers (Daus \& Joplin, 1999) used the WOCS to measure coping, specifically as a potential mediator in their investigation of the relationship between self-reliance and team performance and satisfaction. The researchers administered the WOCS to a sample of undergraduate college students $(N=187)$ in addition to other instruments, including a self-reliance measure, a survival task exercise, and 
statements about task satisfaction and experience. They reported that the interaction between “group members' self-reliance and coping mechanisms" was predictive of group effectiveness (p. 24), and that they did not have statistical evidence for the mediating role of coping as originally hypothesized. The WOCS and revised versions of this instrument continue to be used by researchers investigating coping (e.g., Yi, Smith, \& Vitaliano, 2005); however, other measures such as the COPE (Carver, Scheier, \& Weintraub, 1989) and the Multidimensional Coping Inventory (MCI; Endler \& Parker, 1990) have also been developed and are used by researchers conducting research in the social sciences.

Carver, Scheier, and Weintraub (1989) developed the COPE, a coping instrument that contains items that correspond with 14 distinct dimensions of coping. The dimensions are: 1) Active coping; 2) Planning; 3) Suppression of competing activities; 4) Restraint coping; 5) Seeking social support (instrumental); 6) Seeking social support (emotional); 7) Positive reinterpretation and growth; 8) Acceptance; 9) Turning to religion; 10) Focus on and venting of emotions; 11) Denial; 12) Behavioral disengagement; 13) Mental disengagement; and 14) Alcohol-drug disengagement (Carver, Scheier, \& Weintraub). This instrument was later modified so that it could be completed in a shorter amount of time, and this version is commonly referred to as the Brief COPE (Carver, 1997). The Brief COPE decreased the number of items to two items per scale and revised the names of some of the dimensions; the developer of this modified COPE instrument conducted reliability analyses across three administrations of the instrument and found all reliabilities to meet or exceed a .50 value and demonstrated acceptable internal reliability with a sample of individuals dealing with the aftermath of Hurricane Andrew (Carver). 
The Multidimensional Coping Inventory (MCI) by Endler and Parker (1990) appeared in the literature shortly after the COPE. Initially, the researchers and their colleagues created a list of possible items for the instrument, and then conducted a factor analysis to cut the total item number down to 44 items across three subscales: 1) Task (19 items); 2) Emotion (12 items); and 3) Avoidance (13 items). Reliability and validity statistics were presented, as the researchers claimed that previous coping instruments were weak in psychometric properties. Among the reported descriptive statistics were the alpha coefficients for each subscale and test-retest correlations. Alpha coefficients ranged from .76 on the Emotion subscale (for men) to .91 on the Task subscale (for women). The researchers deemed these coefficients to be highly satisfactory based on Nunnally's (1978) guidelines (Endler \& Parker).

Endler and Parker (1990) also reported test-retest reliability statistics with a sample of male and female undergraduate students $(\mathrm{N}=64)$ who completed the measure on two separate occasions, eight weeks apart. The Emotion (.66), Task (.74), and Avoidance (.68) subscales testretest correlations were reported as "relatively stable over time" (p. 847). Additionally, the researchers conducted a $t$-test of group differences. While they did not identify any gender differences for task coping, they did report that the women in their sample scored higher on the emotion and avoidance coping subscales of the MCI than did men (Endler \& Parker). The MCI thus represents the multidimensional nature of the coping process and suggests that gender differences in coping behaviors within certain contexts may exist. Sport provides one context for exploring gender differences in coping.

\section{Gender Differences in Coping in Sport}

Some researchers have explored the extent to which specific stressors or stressful situations can influence performance in sport and the strategies commonly implemented to cope 
with such demands. Across the studies described, there is evidence for gender differences in coping behavior. For example, Goyen and Anshel (1998) attempted to identify various sources of acute stress for men and women competing in the sport environment, as well as to explore the coping strategies utilized by these individuals in their efforts to deal with stress. The researchers used a two-part questionnaire that borrowed items from several existent coping scales. Samples of adolescents $(N=74)$ and adults $(N=65)$ completed the measures, and the researchers found that male participants reported experiencing higher acute stress levels in comparison to females, and adolescents experienced greater stress intensity than did older adults. Although male athletes used more problem-focused coping than female athletes (who used more emotionfocused coping), adolescent male athletes utilized emotion-focused coping more often than adolescent female athletes for the specific stressor described as "my opponent just cheated" (p. 473). The study indicates that gender differences may or may not be apparent at different stages of development and at least partly influenced by the initial source of any specific stressor.

Crocker and Graham (1995) conducted a study of coping among male and female athletes $(\mathrm{N}=235)$ using self-report instruments such as the COPE (Carver, Scheier, \& Weintraub,1989) and the Positive Affect and Negative Affect Schedule (PANAS; Watson, Clark, \& Tellegen, 1988). The participants indicated stressful situations that they had recently experienced, and elaborated on their cognitive appraisals, coping methods, and affective responses. The strategies that were most commonly used across all groups were: (a) planning; (b) increasing effort; (c) active coping; (d) suppressing competing activities; and (e) self-blame. However gender differences were also prominent. The women in the sample reported higher levels of seeking social support for emotional reasons and increasing effort to handle their frustration with unmet goals. In contrast, men reported higher level of positive affect than did females despite the 
absence of more problem-focused coping (Crocker \& Graham, 1995). This research therefore corroborates some of the early work on gender differences in coping as well as added insight related to coping strategies in sport.

Nicholls, Polman, Levy, Taylor, and Cobley (2007) explored specific stressors, coping behaviors, and coping effectiveness as they relate to gender as well as other demographic factors such as sport type and skill level among a sample of undergraduate athletes $(N=749)$. Using concept maps as the primary assessment tool, the researchers asked each participant to identify a) the stressors they have faced and b) the strategies they have used to cope with those stressors, which were all recorded in blank concept map outlines provided at the time of data collection. The researchers identified and described multiple gender differences after completing both inductive and deductive analyses. Specifically, the Nicholls et al. reported that male athletes indicated using more blocking, such as isolating or deflecting (e.g., Gould, Finch, \& Jackson, 1993), than did female athletes, and female athletes used more communication, planning, and technique-oriented coping strategies. With these results in mind, the researchers suggested that men and women do not always use more problem-focused coping and emotion-focused coping, respectively (Nicholls et al.). Rather, their use of coping strategies may be determined by other internal or external factors.

Tamminen and Holt (2010) conducted a study to investigate recurring and/or ongoing stressors and the selected coping strategies that individuals utilized to deal with stress over an entire athletic season. The researchers conducted this study with active female basketball players $(N=13)$, each of whom participated in interviews with the researchers and kept audio-based logs throughout the season. The researchers reported that most of the athletes used reactive coping strategies and not proactive coping strategies when faced with stress; the strategies of planning 
and evaluation were the two distinguishing differences between the groups who used reactive versus proactive strategies. The definitions and categorization of these two approaches may be meaningful to future researchers looking to differentiate coping strategies from one another without the use of the more common "problem-focused" and "emotion-focused" labels.

Although the researchers did not use males in their sample, their results indicate a pairing of the female gender with emotion-focused coping. This finding might suggest that the females attend to the emotional distress involved in coping more so than they attempt to change or solve their stressful situation logically and analytically, which might be stereotypically expected of male athletes (e.g., Hammermeister \& Burton, 2004). Clearly, gender differences in coping in sport are a topic of interest, and one that requires further investigation. In order to best examine these differences, researchers will need to develop sport-specific instruments themselves, or rely on the several instruments already published in the sport science literature that appear to assess coping as it relates to sport and the athletic environment.

\section{Measuring Coping in Sport}

In addition to developing general coping instrumentation, such as the COPE (Carver, Scheier, \& Weintraub, 1989), researchers have also developed more specific coping instruments that assess coping in sport settings (e.g., Crocker \& Graham, 1995; Gaudreau \& Blondin, 2002; Kowalski \& Crocker, 2001; Smith, Schutz, Smoll, \& Ptacek, 1995). For instance, Crocker and Graham developed a modified version of the COPE, called the MCOPE, which is a sport specific measure of coping (Eklund, Grove, \& Heard, 1998). The measure consists of nine scales from the original COPE and three scales from the sport version of the Ways of Coping scale (Gaudreau \& Blondin). Eklund et al. examined the MCOPE's psychometric properties, as the instrument relates to "slump-related coping tendencies" (p. 173), with a sample of athletes $(N=$ 
621) who trained an average of six hours per week for 34 weeks per year. The athletes completed the 48-item instrument that consisted of 12 distinct coping strategies via a 5-point scale $(1=$ not used at all, $5=$ used very much $)$. The researchers reported that their crossvalidation analyses revealed the instrument's desirable psychometric properties, including factory validity, however there exists room for improvement. For instance, there were few differences among the four competing models of the MCOPE proposed and tested in the study (Eklund et al.). Research scholars and applied sport psychologists thus need to continue to evaluate its applicability to sport-specific research.

Another sport-specific instrument related to coping in sport is the Athletic Coping Skills Inventory-28 (ACSI-28; Smith, Schutz, Smoll, \& Ptacek, 1995). The researchers developed the ACSI-28 to serve as a multidimensional measure of psychological skills in sports. They incorporated seven sport-specific subscales in the measure, each with four items that are answered with a 4-point Likert scale $(0=$ almost never, $3=$ almost always $)$. The subscales are: 1) Coping with adversity; 2) Peaking under pressure; 3) Goal setting/Mental preparation; 4) Concentration; 5) Freedom from worry; 6) Confidence and Achievement motivation; and 7) Coachability. From this instrument, researchers can measure coping skills on seven subscales and calculate a total scale score by adding up the scores for each of the 28 items. The instrument has been deemed valid and reliable (Smith et al., 1995) and has been used to study coping in sport (e.g., Mummery, Schofield, \& Perry, 2004; Omar-Fauzee, Daud, Abdullah, \& Rashid, 2009). Perhaps one of the instrument's strongest characteristics is its sport-specific nature, as it was developed for the sport population; on the other hand, it was not developed from any specific theory of stress and coping, and as such is multidimensional but not theory-driven (Croker, Kowalski, \& Graham, 1998). 
Kowalski and Crocker (2001) developed the Coping Function Questionnaire (CFQ) for adolescents in sport upon acknowledging that many coping scales were not conducive to assessing coping behavior among adolescents and within a sport-specific context. The researchers initially developed 30 items related to problem-focused, emotion-focused, and avoidance coping strategies, and after modifications, tested a 19-item scale with teenage athletes $(N=15)$ in a pilot study. The pilot study resulted in no formatting concerns, and the researchers subsequently tested the psychometric properties of the CFQ with two different sample populations. They reported that the instrument's means, variances, and distributions were "acceptable and consistent for items within scales," and that the comparative fit index for the three-factor model for boys and girls were .91 and .88, respectively (pp. 148-150). The resulting CFQ after these two studies was an 18-item questionnaire that could be used across samples of adolescent athletes. Crocker and Kowalski (2001) claim that among its strongest characteristics is the instrument's ability to assess coping function compared to identifying coping strategy.

Gaudreau and Blondin (2002) developed a self-report instrument called the Inventaire des Stratégies de Coping en Compétition Sportive (ISCCS) shortly after the development of the CFQ. This instrument was intended to assess the coping strategies that athletes employ in the competitive sport environment, and was first tested with a sample $(N=316)$ of French-Canadian athletes within six hours of a competition. Subsequent analyses showed that the proposed instrument could be refined with 10 coping subscales, namely: 1) Thought control, 2) Mental imagery, 3) Relaxation, 4) Effort expenditure, 5) Logical analysis, 6) Seeking support, 7) Venting of unpleasant emotion, 8) Mental distraction, 9) Disengagement/resignation, and 10) Social withdrawal. The researchers provided definitions and descriptive statistics for each of these subscales as well as correlations between the ISCCS subscales and both the MCOPE and 
WOCS subscales. They reported that Cronbach's alpha coefficients for internal consistency ranged from .67 to .87 among the 10 subscales. The researchers suggested that the ISCCS could contribute to the existing literature on coping strategies for both individual and team sports (Gaudreau \& Blondin) and that additional qualitative research in particular might help to deepen participants' responses. It is also possible that using the ISCCS to conduct research with sports team leaders might reveal interesting findings with respect to the 10 coping subscales, given the nature of leadership in both general and sport-specific contexts.

\section{Defining Leadership}

Leadership has been generally defined as "a process whereby an individual influences a group of individuals to achieve a common goal" (Northouse, 2004, p. 3). The construct typically involves four different components; leadership is a process, leadership involves influence of another, leadership occurs between and among more than one person (it is interpersonal), and it includes some sort of shared mission or goal to be executed or achieved (Chelladurai, 1990; Todd \& Kent, 2004). Similar to the types of coping that were previously described, leadership can be broken down into categories or subtypes, with the most common two being transactional and transformational. Bass (1980) describes transactional leadership in the business and organizational domains as leadership that consists of informational exchanges specifically related to reward or punishment based on performance. The "transactions" between manager and employees are deemed to be in some cases passive and uninspiring, and perhaps "prescription[s] for mediocrity" (p. 20).

Hence transformational leadership might come more highly recommended for leaders operating in various settings such as the workplace and athletics. This latter type of leadership occurs when individuals "broaden and elevate the interests" of others and "generate awareness 
and acceptance of the purposes and mission of the group, and... look beyond their own selfinterest" (Bass, 1980, p. 21). From these two descriptions, one can observe the ongoing, positive influence that transformational leaders may be capable of having in comparison to the structured, periodic interactions that may occur with transactional leadership. Although both have their advantages in specific circumstances, this review of literature will primarily contain research on transformation leadership due to the multidimensional nature of leadership in sport (e.g. Chelladurai, 1990) and the complexity of sport environment itself (e.g., Eitzen \& Sage, 2009).

\section{Leadership Identity and Development}

It is important for researchers and laypersons alike to know more about leadership than its definition and basic description. Given that leadership is a broad concept, researchers (e.g., Judge, Bono, Ilies, \& Gerhardt, 2002; Komives, Owen, Longerbeam, \& Mainella, 2005) have aimed to explore how leaders might develop as people and as leaders, how they may come to be identified by others as leaders, and which specific characteristics and experiences these leaders may share. For example, Komives et al. investigated the development of leadership identity in young adults through grounded theory work by employing an intensity sampling approach to their research question. The researchers first identified a lack of understanding of leadership identity development in the literature, and then aimed to explore the process of creating leadership identity and how individuals experience this process. Specifically, the researchers attempted to provide insight for a theoretical model, rather than simply presenting descriptions of leadership behaviors. To select their participants, the researchers asked university professionals to nominate students whom they believed to be leaders. A group of students $(N=13)$ participated in the qualitative study, which consisted of a series of three interviews conducted across an interview team of five women. 
The resulting model (which the authors presented after categorizing the participants' responses) showed six primary stages of leadership development: 1) Awareness; 2) Exploration or engagement; 3) Leader identified; 4) Leadership differentiated; 5) Generativity; and 6) Integration or synthesis (Komives et al., 2005). These stages were presented in sequential order so as to suggest that leadership develops across time and experience and to a certain degree requires self-reflection and personal insight. Further, the researchers highlighted six sources of leadership identity: 1) Developmental influences; 2) Changing view of self with others; 3) Group influences; 4) Developing the self; 5) Leadership identity; and 6) Broadening view of leadership. The idea of leadership development being represented with a "helix" shape may best explain how leaders revisit their sense of self and reconstruct their identities based on the opportunities they have had to be a leader, and what they have brought to, and learned form, each experience. Judge et al. (2002) have approached the study of leadership identity and development not from a grounded theory approach but from a five-factor personality framework. The researchers conducted a qualitative review and subsequent meta-analysis of research studies examining leadership and personality. Their sample of studies $(N=78)$ was related to either leadership emergence or leadership effectiveness, which the researchers suggested are "related but distinct criteria" (p. 770). When taken together in an overall correlation analysis, emergence and effectiveness were most highly correlated with Extraversion, followed by Conscientiousness, Neuroticism, and Openness to Experience, respectively. The researchers suggested that Extraversion was the most critical factor in the five-factor model with regards to leadership, and that researchers should further investigate this finding because of the role that "talking more" might play in the emergence of leaders (Judge et al.). 
Chan and Drasgow (2001) sought to understand the motivation to lead among leaders in various fields, and presented a "broad theoretical framework for understanding the role of individual differences in leadership behaviors" (p. 481). Their framework hypothesized that factors such as personality, cognitive ability, past experience, and personal resources would contribute to motivation to lead, among other related constructs. The researchers tested individuals' motivation to lead (MTL) with a 27-item self-report questionnaire with several samples: Singapore military recruits $(N=1,594)$, Singapore junior college students $(N=274)$, and American undergraduate students $(N=293)$. The three major factor loadings were identified as affective-identity MTL, non-calculative MTL, and social-normative MTL, with nine items used to assess each factor category. The researchers' analyses led to several major findings related to leadership. Among them was the identification of personality, leadership self-efficacy, past leadership experience, and sociocultural values served as antecedents to MTL and thus may be precursors to leadership development in other samples (Chan \& Drasgow). With an understanding of such findings, future researchers may be able to better hypothesize how and why individuals take on or accept leadership roles across domains.

\section{Defining Leadership in Sport}

Leadership is a popular topic across many domains and fields of study, and sport is one domain through which leadership can be explored. Indeed, there are many leaders within the world of sports including, but not limited to, administrators, athletic trainers, coaches, assistant coaches, and athletes. Chelladurai (1990) was among the first researchers in the field of sport psychology to acknowledge the influence that coaches have on their players and to examine the specific behaviors that coaches might exhibit in their leadership role. Chelladurai published a review of leadership in sports after developing the Multidimensional Model of Leadership 
(MML; Chelladurai \& Saleh, 1978) and developing an instrument to assess leadership in sports, called the Leadership Scale for Sports (LSS; Chelladurai \& Saleh, 1980).

The MML proposed that three categories of leadership behavior exist among coaches, namely required behavior, preferred behavior, and actual behavior (Chelladurai, 1978). The model also described three antecedents to leadership behavior: personal characteristics, situational characteristics, and group member characteristics. Ideally, coaches will exhibit leadership behavior that is required of the situation and preferred by their athletes. The degree of similarity among the three categories (actual, required, and preferred) was proposed by Chelladurai to be influential in satisfaction and performance (Carron, Hausenblas, \& Eys, 2005). Weinberg and Gould (2011) state that the "effectiveness of an individual's leadership style stems from matching the style to the situation," suggesting that a good leader adapts his or her behaviors to a given circumstance and the needs of the members involved in that circumstance (p. 209). It is clear that, between the MML and additional research on leadership and preferred leadership styles, scholars and practitioners can gain a better understanding of leadership and how behavior in the sport context can affect correlates of athletic performance. More specifically, it will be important for scholars and practitioners to explore peer leadership in athletics, as athletes not only serve as one another's teammates, but also as one another's formal and informal leaders (Loughead, Hardy, \& Eys, 2006).

\section{Defining Peer Leadership in Sport}

Peer leadership may be generally described as leadership provided by one or more individuals to a group of one or more other persons within their age group and range of experience, who are aiming to create and achieve individual and group goals (Gould \& Voelker, 2010). For instance, a peer leader in the classroom might be someone who initiates discussion. 
A peer leader in the school band might help to arrange rehearsals and tune everyone before a performance. Peer leadership is a construct that differs from other leadership constructs simply by the nature of its name. Hence it is important that researchers look to approach the construct from a particular theoretical perspective when it is available through the existent literature.

Contrary to the notion that there are only leaders and non-leaders in sport, there are multiple leadership roles in which individuals can serve (Carron et al., 2005). Loughead et al. (2006) have suggested that leadership roles may be organized into two higher-order categories, specifically formal and informal. Formal leadership roles are typically described as those with titles and having specific expectations and tasks to perform. Formal leaders, also called prescribed leaders (Carron et al.), may therefore include captains. Informal leadership roles, by contrast, may not necessarily have titles associated with them, and may vary in expectations and tasks based on group needs, characteristics, and preferences.

For example, individuals who take it upon themselves to help out at practice or to organize community or social events are considered informal leaders. Carron et al. (2005) refer to these individuals as emergent leaders. By "emergent," it is implied that these individuals are not necessary given roles or titles by authority figures such as coaches or managers, but rather are organically and spontaneously self- or other-appointed or recognized as leaders due to their behavior, performance, or character. In order to incorporate the possibility for both formal and informal leadership in the context of sport, Loughead et al. (2006) defined athlete leadership as "an athlete occupying a formal or informal role within a team who influences a group of team members (i.e., a minimum of two team members) to achieve a common goal"' (p. 144).

Loughead et al. (2006) conducted a study with the purpose of exploring leadership characteristics for team (formal) and peer (informal) leaders across task, social, and external 
functions. They also set out to determine the amount of leadership present on sports teams and to identify the consistency and stability of leadership across a full season for all of the participants' teams. The researchers conducted their study with a sample of intercollegiate varsity athletes $(N=258)$ from two universities, which represented a total of 13 sports teams. The athletes nominated leaders on their teams, and this method was employed for formal and informal leaders across the three specific functions; the researchers prompted all participants by asking them to "list the names of team members (including yourself if applicable) you feel most strongly contribute to your team's task/social/external factors. That is, please list team members who do or have done at least one, some, or all of the following actions" (p. 149). A list of possible leadership actions followed the prompt so that participants could identify the actions typically displayed by their team members. A demographic questionnaire was also used to gather team and demographic information for the data analysis phase.

Loughead et al. (2006) calculated dispersion coefficients for team and peer leadership within their sample, and their results indicated that formal and well as informal leaders are present and influential on sports teams. "Team leaders" within the study were likely to be captains at the third year of tenure in school and had the highest percentage of team external ratings among all participants. "Peer leaders" represented a high percentage of social leadership and were fairly stable over time, although this only applied to a core number of athletes (attrition occurred over the course of the season for many teams). This research showed how athletes can serve in formal and informal leadership roles on any given team, and that their peers can (to a certain extent) identify their responsibilities, effectiveness, and stability through self-report instrumentation. 
Researchers Price and Weiss (2011) further explored the topic of peer leadership by examining the constructs of perceived competence, intrinsic motivation, behavioral conduct, and peer acceptance in relation to peer leaders' own, and their teammates', ratings of peer leadership within the sport context. The researchers also sough to examine the possible relationships among peer leadership behavior ratings with collective efficacy and team cohesion. A sample of female adolescent soccer players $(N=191)$ from competitive travel teams of United States Youth Soccer who were active in U-15 to U-18 age groups participated in the study, and were asked to provide responses to several quantitative, self-report instruments in the middle of the season. The instruments used to measure and assess each of the major constructs of interest included the athletic, behavioral conduct, and social acceptance subscales of the Self-Perception Profile for Adolescents (Harter, 1988), the challenge and curiosity/interest subscales of the Motivational Orientation in Sport scale (Weiss, Bredemeier, \& Shewchuk, 1985), the Group Environment Questionnaire (GEQ; Carron, Widmeyer, \& Brawley, 1985), the Collective Efficacy Questionnaire for Sports (CEQS; Feltz \& Lirgg, 1998), the Sport Leadership Behavior Inventory (SLBI; Glenn \& Horn, 1993), and the Peer Sport Leadership Behavior Inventory (PSLBI; Glenn, 2003).

The factor analyses run by the researchers revealed several findings. First, those participants who reported higher levels of peer acceptance, intrinsic motivation, and perceived sport competence were rated by their teammates as using more frequent instrumental leadership behaviors (Price \& Weiss, 2011). These athletes also saw themselves as using more leadership behaviors, and reported greater social cohesion within their teams. The researchers suggested that these findings "mean that team members associate leadership behaviors with peers who are confident in their soccer abilities, are liked by others, prefer challenging tasks to easy ones, and 
act in behaviorally appropriate ways" (p. 60). From this statement, it is implied that researchers should attempt to identify how peer relations in sport may allow for leadership to occur and develop among and within teams. Applied practitioners and coaches may also be able to identify and capitalize on the behaviors of those athletes who show leadership potential.

In conclusion, defining peer leadership may prove to be a rather complex endeavor, given the overlap with other leadership research, as well as the limited exploration of formal and informal athlete leaders. However, research from the past decade has helped us to gain a better understanding of peer leadership and its importance to the sport sciences. Definitions such as Loughead et al.'s (2006) are likely to be put to use as scholars advance their knowledge of the athlete leadership construct and disseminate new information to practicioners and the general public.

\section{A Theoretical Approach to Peer Leadership}

Price and Weiss (2011) suggested that transformational leadership might serve as a useful theoretical lens through which to observe and understand peer leadership in sports. The researchers articulated that transformational leadership implies a "leader-follower relationship" (p. 51) that is often evident among peer groups in which some peers take the lead and others have the tendency to follow that lead. Additionally, the four main factors of transformational leadership are appropriate for a sport context given their applicability to peer interactions. These four factors are: 1) Idealized influence, 2) Inspirational motivation, 3) Intellectual stimulation, and 4) Individualized consideration (Zacharatos, Barling, \& Kelloway, 2000). This stands in contrast to transactional leadership, which is much more focused on the exchange of information or rewards (e.g., Bass, 1990). Bass asserts that transformational leadership is equivocal to "superior leadership performance" in the organizational domain given that it entails leaders 
broaden[ing] and elevat[ing] the interests of [others]" (p. 21), which could be beneficial in the context of sport, given the importance of developing cohesion among teammates.

In order to better understand the construct of transformation leadership, and specifically how it develops or is acquired, Zacharatos et al. (2000) conducted a study of transformational leadership among youth and the extent to which their transformational leadership behaviors were a product of parent-child relations. Using a social learning theory framework, they developed their hypotheses based on the assumption that children have the ability to learn transformational leadership qualities and behaviors from their parents, with whom they are assumed to have regular, experiential, meaningful contact. Participants were youth athletes $(N=112)$ as well as their coaches and peers. The youth athletes reported their perceptions of their parents' childrearing behaviors, the coaches reported evaluations of individual athletes' behaviors, and peers gave evaluations of their peers' observed behaviors.

The researchers' findings included the idea that transformational leadership skills can be learned through observation. Specifically, the researchers found the youth athletes' fathers to be most influential in learned behaviors. The researchers also reported that because young children can learn and exercise transformational leadership behaviors, there may be implications for future leadership in these individuals' lives and endeavors as they become older and have new experiences (Zacharatos et al., 2000). Despite their dependence on self-report instrumentation and a relatively small sample size, the researchers corroborated the belief that athletes can indeed exhibit leadership behaviors that they have learned through socialization. This study supports the notion that acquired leadership skills can be observed over time and experience and therefore might inform coaches and athletes alike about the ways in which leaders can develop and emerge in the sport environment when given positive role models and opportunity. 


\section{Research on Peer Leaders in Sport}

Over the past few decades, many researchers have investigated peer leadership in sport (e.g., Dupuis, Bloom, \& Loughead, 2006; Holmes, McNeil, Adorna, \& Procraccino, 2008; Grandzol, Perlis, \& Draina, 2010; Voelker, Gould, \& Crawford, 2011). Researchers studying peer leadership in sport have employed quantitative, qualitative, and exploratory methodologies, and their results have contributed to the growing knowledge of peer leaders. For instance, Dupuis et al. (2006) aimed to explore the leadership behaviors that are expressed by formal athlete leaders in a sport context. The researchers wanted to identify the traits that were most prominent and examine the behaviors of formal leaders in sport. A sample of six former intercollegiate Canadian male ice hockey players, all of who had been team captains, participated in semi-structured interviews. Specific criteria for participation included at least a 50\% wining record while serving as a captain, as well as having played at the university level for at least two seasons (and one as a captain). The coaches of these players nominated the captains for participation, therefore the sample might be described as both selective and convenient.

The researchers transcribed the interview verbatim with the exception of removing identifying information from the transcriptions. They then identifying meaning units that were “tagged based on... content" and grouped these tags into larger groups, which they called "properties," and ultimately into categories (Dupuis et al., 2006, p. 66). The researchers went from 425 meaning units to 3 categories, with the latter group representing interpersonal skills, verbal interaction, and task behavior as important leadership factors. Additionally, the researchers stated that the participants emphasized that good communication is key, as is timing and quality of communication (in contrast to quantity of their feedback to others). While the sample size is an obvious limitation of this study, the results uphold the notion that leadership is 
an important construct to investigate and that further examination of leadership among female sport participants and other support staff members should be conducted (Dupuis et al.).

Another study by Holmes et al. (2008) examined student athletes' perceptions and preferences for peer leadership at the collegiate level both on and off of the field. The researchers utilized a revised version of the Leadership Scale for Sports (LSS; Chelladurai \& Saleh, 1980) called the RLSS (Zhang, Jensen, \& Mann, 1997) as well as two appended, openended questions for the purpose of peers nominating athlete leaders on and off the field. The researchers had a sample of male $(N=33)$ and female $(N=46)$ collegiate athletes from the same northeastern university with a reported average age of 19.58 years. The researchers coded the open-ended responses by grouping verbatim phrases together into categories, and the RLSS and participant demographics were analyzed by conducting MANOVAS for each of the variables.

The researchers ultimately found gender differences in autocratic behaviors, with males being more likely to report preferring these behaviors than women (Holmes et al, 2008). Also, the researchers found that working hard in sport and setting a good example for others were two important characteristics of on-field leaders, and a positive personality was important for those leaders during activities off the field (particularly for women). The researchers stated that the study had many limitations, including unequal gender composition, and homogeneity of ethnicity within the sample. They also stated that the exploratory nature of the study makes it difficult to extrapolate or generalize any particular findings to other sample populations within the sport science literature.

Grandzol, Perlis, and Draina (2010) sought to explore the development of leaders through participation in NCAA Division III athletics by contacting twelve Athletic Directors from members institutions of an athletic conference in Pennsylvania. The researchers were interested 
in the experiences of both student-athletes and team captains $(N=162)$ at the pre- and post-test time periods. The researchers used the Student Leadership Practices Inventory (Student LPI; Kouzes \& Posner, 2005) to assess leadership practices, namely: 1) Encourage the heart; 2) Enable others to act; 3) Model the way; 4) Inspire a shared vision; and 5) Challenge the process. Upon analyzing the data with repeated-measures ANOVA, the researchers found that the mean scores for team captains were higher than the means for student-athletes across the five leadership practices at both time periods, with the team captains' scores increasing over time. The study provided evidence for the notion that giving team members leadership positions, such as team captain, results in increased leadership behavior (Grandzol, Perlis, \& Draina, 2010). Scholars might look to replicate and expand on this study, given its limited scope with respect to sample size and number of universities contacted. Applied practitioners may also benefit from this research, as sport psychology consultants might work with athletes serving in, coping with, or seeking to occupy leadership roles.

Voelker et al. (2011) undertook a study with the aim of capturing the experiences of high school sports captains serving in leadership roles on a variety of teams. The researchers strove to better understand what the role of captain means to these individuals and how they perceive their role as being effective. Each participant $(N=13)$ engaged in a semi-structured interview, which lasted between 60 and 90 minutes. The researchers found that being a captain has positive and negative connotations, requirements, and role characteristics. Participants cited responsibility and accountability as one of the most difficult aspects of captaincy, while all 13 reported that organizing on and off-field events/drills was the primary perceived duty of a captain. Surprisingly, few participants in this study believed that they were given opportunities to lead, which has implications for coaches and athletic trainers; adult leaders in coaching and support 
staff roles might consider re-evaluating the dynamics of their teams and how power, decisions, and opportunity are distributed among all participants. Developing good relationships, setting good examples, and communicating well were among the most popular responses when discussing recommendations for future captains in this study (Voelker et al.), and so giving athletes opportunities to display these behaviors might benefit their respective teams.

With new knowledge of peer leadership in the context of sport, researchers are beginning to conduct leadership workshops, seminars, and training curricula for athletes and their coaches. For instance, Gould and Voelker (2010) created an annual leadership workshop (the MHSAA Captain's Leadership Training Program) for youth sport leaders competing at the high school level as a result of the partnership between the Institute for the Study of Youth Sports (ISYS) and the Michigan High School Athletic Association (MHSAA). They published a commentary following their fifth year of the workshop in which they articulated the development, execution, improvements, and future directions of the event (Gould \& Voelker, 2010). Robert Morris University, near Pittsburgh, PA, has also served as the host site of a student-athlete leadership conference for the past several years (Kimball, 2011, personal communication). It is therefore important that researchers continue to share their findings with colleagues in both the research and applied realms of sport psychology so that theory can be implemented into practice among consultants, coaches, and athletes. It is relatively clear from research of peer leaders in sport that leadership among athletes has positive implications for leadership development. Recently, researchers have also investigated the relationship between leadership and sport performance.

\section{Peer Leadership and Performance Factors}

In the past decade, many studies have been published on peer leadership and various performance factors, including athlete satisfaction (Eys, Loughead, \& Hardy, 2007), team 
cohesion (Vincer \& Loughead, 2010), and competitive trait anxiety (Horn, Glenn, \& Campbell, 2010), among other factors. To elaborate, Eys et al. (2007) explored the potential relationship between athlete leader dispersion (i.e., the perceived number of peer leaders on a sports team as indicated by participants) and athlete satisfaction at two time periods (i.e., the beginning and end of a competition season). The researchers asked varsity student athletes $(N=218)$ to indicate the peers who fulfilled task, social, and external leadership roles on their teams via three open-ended questions and to complete a four dimensions of a self-report measure of satisfaction, namely the Athlete Satisfaction Questionnaire (ASQ; Riemer \& Chelladurai, 1998). Upon analyzing the collected data by running cluster analyses, Eys et al. (2007) found that participants who reported having a fairly balanced number of peers serving in leadership roles across the task, social, and external functions of leadership also reported greater satisfaction.

Moreover, the researchers found that those who perceived the task, social, and external functions to be equally represented within their team had increased levels of satisfaction. Eys et al. (2007) therefore suggested that athletes are most likely to be satisfied with their team, and their participation within it, when their peers can "properly attend to and balance both task and social elements" in the sport environment (p. 293). It should be noted, as it is by the researchers, that the study does not explore the quality of the leadership reported, but rather only the quantity of leaders and leader types (Loughead et al., 2007). Additional studies conducted by researchers who aim to explore both the quantitative and qualitative facets of this topic might provide athletic directors, coaches, and athletes with a better picture of leadership as it emerges and exists within sports teams.

Vincer and Loughead (2010) conducted a study to explore if and how athlete leadership relates to perceptions of team cohesion in adolescent/young adult athletes. The researchers used 
a sample of athletes $(N=312)$ from a large pool of 25 athletic teams, with a reported average age of 19.21 years. The measures included the Group Environment Questionnaire (GEQ; Widmeyer, Brawley, \& Carron, 1985) and the LSS (Chelladurai \& Saleh, 1980) for instrumentation of the major variables of interest, and these were counterbalanced to eliminate the potential for ordering effects to influence the outcome(s). The researchers found that athlete leadership influences cohesion; in fact, all four dimensions of cohesion were positively related to peer social support and training and instruction. A negative relationship was found between peer leadership behaviors and autocratic behavior, suggesting that peer leaders may differ meaningfully from coaches (given that autocratic coaching can be utilized in team sport settings). Limitations of this study, according to the researchers, are the convenience sampling of 40 coaches (and their respective athletes), the departure from the initial intention of the LSS (for coaches, not for peer leaders), and the fact that we cannot make any causal statements related to the results.

Horn, Glenn, and Campbell (2010) conducted a study to explore perceptions of peer leader behavior, competitive trait anxiety, and achievement goal orientation among a sample of female soccer players $(N=208)$ competing at the elite level. The researchers used an adapted version of the Leadership Scale for Sports (LSS; Chelladurai \& Saleh, 1980), the Sport Anxiety Scale (SAS; Smith, Smoll, \& Schultz, 1990), and a sport-specific version of the Task and Ego Orientation in Sport Questionnaire (TEOSQ; Duda \& Nicholls, 1992), to assess these three constructs. They subsequently concluded that their results showed a positive relationship between democratic leader behavior, social support, and positive feedback and increased levels of both mastery goal orientation and performance goal orientation. Athletes who reported that their peer leaders used a more autocratic style of leadership indicated higher self-report levels of competitive trait anxiety than those athletes who reported having fairly democratic peer leaders. 
The researchers stated that their results were "consistent with both achievement goal theory and social cognitive anxiety theory," and they supported the notion that "the behaviors and leadership styles exhibited by sport peer leaders do affect their teammates' levels of anxiety and achievement goal orientation" (Horn et al., 2010, p. 239). The researchers acknowledge some limitations of their study, however, noting that their sample of adolescent girls restricts the ability to generalize the results. Their findings also might look different if the procedure were conducted with participants competing at a different skill level or playing a different sport. Nevertheless, the results illustrate an interesting relationship between peer leadership and anxiety, and examining the constructs of leadership and coping in sports may therefore be a worthwhile endeavor.

\section{Leadership and Coping}

Within the sport and exercise psychology literature, there exist gaps between the research areas of peer leadership and coping. Although some researchers may investigate characteristics and qualities of leaders that may align with particular coping styles or strategies, research that specifically aims to explore both topics in tandem remains warranted. Evidence of joint inquiry related to leadership and coping can be found in fields outside of the sport sciences, such as in consulting psychology and the military. For example, Pratch and Jacobowitz (1996) conducted a quantitative study of personality and leadership in a sample $(N=48)$ of women and men aged 23 to 37 years who were serving as facilitators in a 9-month intensive Leadership Education and Development (LEAD) program within a graduate school of business. The researchers used several instruments to assess these constructs, including the Shanan Sentence Completion Technique (SCCT; Shanan, 1965, as cited in Pratch \& Jacobowitz) to assess the coping dimensions of the participants' personalities. Data analysis consisted of running several 
correlations and ANOVAs to examine potential relationships and gender differences with respect to coping and motivation.

Pratch and Jacobowitz (1996) observed a positive correlation between active coping and overall leadership effectiveness for both men and women, which may be an important relationship to acknowledge for those seeking to occupy-- or selecting individuals to occupy-leadership positions. The researchers noted that replication of the study using "groups with different demographic characteristics" could potentially provide greater insight related to leadership emergence across several vocations and cultures (p. 217). One such group that might benefit from further research on active coping and leadership is the military. Military service requires a certain capacity to handle transitions and to operate within a system that emphasizes loyalty, teamwork, and hierarchy (Greene, Buckman, Dandeker, \& Greenberg, 2010). Atwater and Yammarinol (1993) conducted a study of coping behavior among male and female military leaders $(N=107)$ in their junior or senior year of college. The researchers described these leaders as being responsible for 11 to 13 subordinates and reported to 11 supervisors during a summer training period. The researchers collected data on personality, coping, athletic experience, and leadership with instruments including The Sixteen Personality Factors Test (16PF; Catell, 1950) and the Myers-Briggs Type Indicator (MBTI; Myers \& McCaulley, 1986) (both as cited in Atwater \& Yammarinol, 1993), The Constructive Thinking Inventory (CTI; Epstein \& Meier, 1989), a self-report item related to level of previous sport participation, and a modified version of the Multifactor Leadership Questionnaire (MLQ; Bass \& Avolio, 1990).

The researchers equated "coping" with "practical intelligence" in their study, and suggested that emotional coping is one form of practical intelligence. Their analyses consisted of descriptive statistics, correlations, and multiple regression analyses. The researchers reported 
that emotional coping related to emotional stability, and that this finding relates to past research that showed that leaders generally have greater emotional stability when compared to nonleaders. Atwater and Yammarinol (1993) therefore proposed that emotional stability might be related to leadership effectiveness given that a correlate of leadership, self-confidence, has been shown to relate to emotional coping.

The researchers also found that raters evaluated the leaders who matched their concept of a preferred or ideal leader to be highly transformational and transactional (Atwater \& Yammarinol, 1993). Interestingly, although it was likely that the new subordinates were unaware of their leaders' prior sport participation, the subordinates rated those leaders who had participated in varsity sports as transformational and transactional. The researchers conducted informal interviews with the leaders after-the-fact, and reported that those leaders who had been involved in sports attributed their knowledge of teamwork and motivation to their past participation. This anecdotal evidence is important for future military and sport research, as it indicates the transcendence of leadership experience and behaviors across domains and the development of positive traits and strategies that may result from involvement in these fields. One limitation may be the extent to which there exists a "rigid chain of command" in military settings compared to sport settings (p. 664), and if this variable affects leadership development.

Alarcon, Lyons, Schlessman, and Barelka (2012) recently conducted another study that focused on military leadership. The researchers studied leadership and coping in a sample of Air Force officers in order to better understand these individuals and their coping behavior. The researchers identified two types of leadership, namely transformational and transactional, and assessed these types using the Leadership Profile Measure (LPM; Thurrell, 2010). They claimed that transformational leadership is concerned with the emotional aspects of leadership that 
involve "positive emotions such as motivation and morale" (p. 34) whereas transactional leadership is more closely associated with problem-solving since it is concerned with the transactions between individuals that often involve "conventional economic or rational means such as rewards and punishments" (p. 31). The researchers ran correlational analyses to determine the possible relationships among participants' leadership styles and coping strategies, and a hierarchical regression was used to determine statistical significance.

The researchers found that more than half of the transformational leadership subscales had significant, inverse relationships with "negative emotion-focused coping, including denial, behavioral disengagement, and mental disengagement" (Alarcon et al., 2012, p. 38). The researchers found transformational leadership and positive reinterpretation to be significantly related to one another. Additionally, the researchers reported that all of the problem-focused coping strategies in the study were significantly related to transactional leadership. The researchers articulated that this particular finding underscored the commentary by Lazarus and Folkman (1984), which suggested that effective leaders are those leaders who face problems rather than avoid them and therefore are typically employing problem-focused coping strategies to overcome obstacles (Alarcon et al.).

\section{Summary}

This review of literature was intended to provide an overview of the stress-coping paradigm and peer leadership, in general and sport-specific contexts. The definitions, procedures, instrumentation, and conclusions identified and described in the previous pages are the foundation on which future research can be constructed. The expressed findings and limitations alike can inform scholars and practitioners of the depth, complexity, and importance 
of these factors or constructs, and stimulate additional investigation of the co-occurrence of them within basic and applied settings.

It is anticipated that researchers who conduct quantitative and qualitative studies that examine coping and leadership within the college population in particular will be capable of updating some of the previous literature, and enhance the knowledge of coaches, athletic trainers, sport psychologists, and athletes whom are interacting at all levels of competition. The present gap in the literature between coping and leadership, especially within the college club sports environment, must be filled. Additionally, as is evidenced by research on gender differences in coping in sport (e.g., Goyen \& Anshel, 1998; Crocker \& Graham, 1995; Nicholls et al., 2007), investigations of male and female peer leaders is needed to clarify the assumptions that we make about gender, coping, and leadership, and to provide evidence-based strategies to identify, support, and advance present and future leaders. 


\section{References}

Alarcon, G. M. (2012). Leadership and coping among Air Force officers. Military Psychology, 24(1), 29.

Allen, M. S., Greenlees, I., \& Jones, M. (2011). An investigation of the five-factor model of personality and coping behavior in sport. Journal of Sports Sciences, 29(8), 841-850.

Anshel, M. H. (1996). Coping styles among adolescent competitive athletes. Journal of Social Psychology, 136(3), 311-323.

Anshel, M. H. (2012). Sport psychology: From theory to practice ( $5^{\text {th }}$ ed.). Boston, MA: Benjamin Cummings.

Anshel, M. H., \& Sutarso, T. (2007). Relationships between sources of acute stress and athletes' coping style in competitive sport as a function of gender. Psychology of Sport and Exercise, 8, 1-24.

Anshel, M. H., Sutarso, T., \& Jubenville, C. (2009). Racial and gender differences on sources of acute stress and coping style among competitive athletes. The Journal of Social Psychology, 149(2), 159-177.

Atwater, L. E., \& Yammarinol, F. J. (1993). Personal attributes as predictors of superiors' and subordinates' perceptions of Military Academy leadership. Human Relations, 46, 645668.

Bass, B. M. (1990). From transactional to transformational leadership: Learning to share the vision. Organizational Dynamics, 18(3), 19-31.

Bass, B. M., \& Avolio, B. J. (1995). The Multifactor Leadership Questionnaire. Palo Alto, CA: Mind Garden.

Bland, H. W., Melton, B. F., Welle, P., \& Bigham, L. B. (2012). Stress tolerance: New 
challenges for millennial college students. College Student Journal, 46(2), 362-375.

Buss, A. H. (1989). Personality as traits. American Psychologist, 44(11), 1378-1388.

Carron, A. V., Hausenblas, H. A., \& Eys, M. A. (2005). Group leadership. In A. V. Carron, H.

A. Hausenblas, \& M. A. Eys (Eds.), Group dynamics in sport (pp. 193-223).

Morgantown, WV: Fitness Information Technology.

Carron, A.V., Widmeyer, W.N., \& Brawley, L.R. (1985). The development of an instrument to assess cohesion in sport teams: The Group Environment Questionnaire. Journal of Sport Psychology, 7, 244-266.

Carver, C. S. (1997). You want to measure coping but your protocol's too long: Consider the brief COPE. International Journal of Behavioral Medicine, 4(1), 92-100.

Carver, C. S., \& Scheier, M. F. (1994). Situational coping and coping dispositions in a stressful transaction. Journal of Personality and Social Psychology, 66(1), 184-195.

Carver, C. S., Scheier, M. F., \& Weintraub, J. K. (1989). Assessing coping strategies: A theoretically based approach. Journal of Personality and Social Psychology, 56, 267-283.

Chan, K. Y., \& Drasgow, F. (2001). Toward a theory of individual differences and leadership: Understanding the motivation to lead. Journal of Applied Psychology, 86, 481-498.

Chelladurai, P. (1990). Leadership in sports: A review. International Journal of Sport Psychology, 21, 328-354.

Chelladurai, P., \& Saleh, S. D. (1980). Dimensions of leader behavior in sports: development of a leadership scale. Journal of Sport Psychology, 2, 34-45.

Creswell, J. W. (2007). Qualitative inquiry \& research design. Thousand Oaks, CA: Sage Publications.

Crocker, P. R. E., \& Graham, T. R. (1995). Coping by competitive athletes with performance 
stress: Gender differences and relationships with affect. The Sport Psychologist, 9(3), $325-338$.

Crocker, P. R. E., \& Graham, T. R. (2005). Coping by competitive athletes with performance stress: gender differences and relationships with affect. The Sport Psychologist, 9(3), $325-338$.

Crocker, P. R. E., Kowalski, K. C., \& Graham, T. R. (1998). Measurement of coping strategies in sport. In Advances in sport and exercise psychology measurement. Joan L. Duda (Ed.). Fitness Information Technology: Morgantown, WV.

Daus, C. S., \& Joplin, J. R. W. (1999). Survival of the fittest: Implications of self-reliance and coping for leaders and team performance. Journal of Occupational Health Psychology, $4(1), 15-28$.

Deisinger, J. A., Cassisi, J. E., \& Whitaker, S. L. (2003). Relationships between coping style and PAI profiles in a community sample. Journal of Clinical Psychology, 59(12), 1315-1323.

Duda. J. L., \& Nicholls, J. G. (1992). Dimensions of achievement motivation in schoolwork and sport. Journal of Educational Psychology, 84(3), 290-299.

Dupuis, M., Bloom, G., \& Loughead, T. (2006). Team captains' perceptions of athlete leadership. Journal of Sport Behavior, 29, 60-78.

Edwards, J. R., \& O’Neill, R. M. (1998). The construct validity of scores on the Ways of Coping Questionnaire: Confirmatory analysis of alternative factor structures. Educational and Psychological Measurement, 58(6), 955-983.

Eitzen, D. S., \& Sage, G. H. (2009). Sociology of North American sport ( $8^{\text {th }}$ ed.). Boulder, CO: Paradigm Publishers.

Eklund, R. C., Grove, J. R., \& Heard, N. P. (1998). The measurement of slump-related coping: Factorial validity of the COPE and Modified-COPE inventories. Journal of Sport and 
Exercise Psychology, 20, 157-175.

Endler, N. S., \& Parker, J. D. A. (1990). Multidimensional assessment of coping: A critical evaluation. Journal of Personality and Social Psychology, 58, 844-854.

Epstein, S., \& Meier, P. (1989). Constructive thinking: A broad coping variable with specific components. Journal of Personality and Social Psychology, 57(2), 332-350.

Etzel, E. (Ed.) (2009). Counseling and psychological services for college student-athletes. Morgantown, WV: Fitness Information Technology.

Eys, M. A., Loughead, T. M., \& Hardy, J. (2007). Athlete leadership dispersion and satisfaction in interactive sport teams. Psychology of Sport and Exercise, 8, 281-296.

Feltz, D. L., \& Lirgg, C. D. (1998). Perceived team and player efficacy in hockey. Journal of Applied Psychology, 83, 557-564.

Fischer, C. T. (2009). Bracketing in qualitative research: Conceptual and practical matters. Psychotherapy Research, 19(4-5), 583-590.

Folkman, S., \& Lazarus, R. S. (1988). Manual for the Ways of Coping Scale. Palo Alto, CA: Consulting Psychology Press.

Frey, M. (2007). College coaches' experiences with stress: "Problem solvers" have problems, too. The Sport Psychologist, 21, 38-57.

Gaudreau, P., \& Blondin, J. P. (2002). Development of a questionnaire for the assessment of coping employed by athletes in competitive sport settings. Psychology of Sport and Exercise, 3, 1-34.

Glenn, S. D. (2003). Filling the leadership void: The impact of peer and coach leaders on team dynamics and performance. Unpublished doctoral dissertation, University of Idaho, Moscow. 
Glenn, S. D., \& Horn, T. S. (1993). Psychological and personal predictors of leadership behavior in female soccer athletes. Journal of Applied Sport Psychology, 5, 17-34.

Goyen, M. J., \& Anshel, M. H. (1998). Sources of acute competitive stress and use of coping strategies as a function of age and gender. Journal of Applied Developmental Psychology, 19(3), 469-486.

Gould, D., \& Voelker, D. K. (2010). Youth sport leadership development: Leveraging the sports captaincy experience. Journal of Sport Psychology in Action, 1, 1-14.

Gould, D., Finch, L. M., \& Jackson, S. A. (1993). Coping strategies used by national champion figure skaters. Research Quarterly for Exercise and Sport, 64(4), 453-468.

Grandzol, C., Perlis, S., \& Draina, L. (2010). Leadership development of team captains in collegiate varsity athletics. Journal of College Student Development, 51(4), 403-418.

Greene, T., Buckman, J., Dandeker, C., \& Greenberg, N. (2010). The impact of culture clash on deployed troops. Military Medicine, 175(12), 958-963.

Hammermeister, J., \& Burton, D. (2004). Gender differences in coping with endurance sport stress: Are men from Mars and women from Venus?. Journal of Sport Behavior, 27, 148164.

Hardy, L. (1996). Testing the predictions of the cusp catastrophe model of anxiety and performance. The Sport Psychologist, 10, 140-156.

Harter, S. (1988). Manual for the Self-Perception Profile for Adolescents. Denver, CO: University of Denver.

Hill, A. P., Hall, H. K., \& Appleton, P. R. (2010). Perfectionism and athlete burnout in junior elite athletes: The mediating role of coping tendencies. Anxiety, Stress, \& Coping, 23(4), 415-430. 
Holmes, R. M., McNeil, M., \& Adorna, P. (2010). Student athletes' perception of formal and informal team leaders. Journal of Sport Behavior, 33(4), 442-465.

Holmes, R. M., McNeil, M., Adorna, P. \& Procaccino, J. K. (2008). Collegiate student athletes' preferences and perceptions regarding peer relationships. Journal of Sport Behavior, 31, $338-351$.

Horn, T. S., Glenn, S. D., \& Campbell, W. (2010). Perceived peer leadership behaviors. Sport Science Review, 19(3-4), 239-263.

IBM Corporation. (2012). Statistical Packages for the Social Sciences, version 21.

Judge, T. A., Bono, J. E., Ilies, R., \& Gerhardt, M. W. (2002). Personality and leadership: A qualitative and quantitative review. Journal of Applied Psychology, 87(4), 765-780.

Kaiseler, M., Polman, R., \& Nicholls, A. (2009). Mental toughness, stress, stress appraisal, coping and coping effectiveness in sport. Personality and Individual Differences, 47, 728-733.

Komives, S. R., Owen, J. E., Longerbeam, S. D., \& Mainella, F. C. (2005). Developing a leadership identity: A grounded theory. Journal of College Student Development, 46(6), 593-611.

Kouzes, J. M., \& Posner, B. Z. (2005). The Student Leadership Practices Inventory (2nd ed.). San Francisco, CA: Jossey-Bass.

Kowalski, K. C., \& Crocker, P. R. E. (2001). The development and validation of the Coping Function Questionnaire for adolescents in sport. Journal of Sport and Exercise Psychology, 23, 136-155.

Larsen, R. J. (2003). Quantifying idiodynamics: A process approach to personality psychology. Journal of Applied Psychoanalytic Studies, 5(4), 405-423. 
Lazarus, R. S. (1999). Stress and emotion: A new synthesis. New York, NY: Springer Publishing Company.

Lazarus, R. S. (2000). Toward better research on stress and coping. American Psychologist, 55(6), 665-673.

Lazarus, R. S., \& Folkman, S. (1984). Stress, appraisal and coping. New York, NY: Springer.

Loughead, T. M., \& Hardy. J. (2005). An examination of coach and peer leader behaviors in sport. Psychology of Sport and Exercise, 6, 303-312.

Loughead, T. M., Hardy, J., \& Eys, M. A. (2006). The nature of athlete leadership. Journal of Sport Behavior, 29, 142-158.

Martens, R. (1987). Science, knowledge, and sport psychology. In D. Smith \& M. Bar-Eli (Eds.). Essential readings in sport and exercise psychology (pp. 457-470). Champaign, IL: Human Kinetics.

Medalie, J. (1981). The college years as a mini-life cycle: Developmental tasks and adaptive options. Journal of American Health Association, 30, 75-90.

Miles, M. B., \& Huberman, A. M. (1994). Qualitative data analysis: An expanded sourcebook. Thousand Oaks, CA: Sage Publications.

Mummery, W. K., Schofield, G., \& Perry, C. (2004). Bouncing back: The role of coping style, social support and self-concept in resilience of sport performance. Athletic Insight, 6(3), $1-18$.

National Center for Education Statistics. Institute of Education Sciences. US Department of Education. Retrieved 9 January 2013 from http://nces.ed.gov/fastfacts/display.asp?id=98

Nicholls, A., \& Polman, R. C. J. (2007). Coping in sport: A systematic review. Journal of Sport Sciences, 25, 11-31. 
Nicholls, A. R., Polman, R., Morley, D., \& Taylor, N. J. (2009). Coping and coping effectiveness in relation to a competitive sport event: Pubertal status, chronological age, and gender among adolescent athletes. Journal of Sport and Exercise Psychology, 31(3), 299-317.

Nicholls, A. R., Polman, R., Levy. A. R., Taylor, J., \& Cobley, S. (2007). Stressors, coping, and coping effectiveness: Gender, type of sport, and skill differences. Journal of Sport Sciences, 25(13), 1521-1530.

Noh, Y. E., Morris, T., \& Andersen, M. B. (2005). Psychological intervention programs for reduction of injury in ballet dancers. Research in Sports Medicine, 15, 13-32.

Northouse, P. G. (2004). Leadership: Theory and practice ( $3^{\text {rd }}$ ed.). Thousand Oaks, CA: Sage.

Omar-Fauzee, M., Daud, W., Abdullah, R. \& Rashid, S. (2009). The effectiveness of imagery and coping strategies in sport performance. European Journal of Social Sciences, 9(1), 97-108. Accessed 23 January at www.ccsenet.org/ijps.

Patton, M. Q. (2002). Qualitative research \& evaluation methods $\left(3^{\text {rd }}\right.$ ed.). Thousand Oaks, CA: Sage Publications.

Penley, J. A., Tomaka, J., \& Wiebe, J. S. (2002). The association of coping to physical and psychological health outcomes: A meta-analytic review. Journal of Behavioral Medicine, 26(6), 551- 603 .

Poczwardowski, A., \& Conroy, D. E. (2002). Coping responses to failure and success among elite athletes and performing artists. Journal of Applied Sport Psychology, 14(4), 313329.

Pratch, L., \& Jacobowitz, J. (1996). Gender, motivation, and coping in the evaluation of leadership effectiveness. Consulting Psychology Journal: Practice and Research, 48(4), 203-220. 
Price, M. S., \& Weiss, M. R. (2011). Peer leadership in sport: Relationships among personal characteristics, leader behaviors, and team outcomes. Journal of Applied Sport Psychology, 23(1), 49-64.

Ptacek, J.T., Pierce, G. R., \& Thompson, E. L. (2006). Finding evidence of dispositional coping. Journal of Research in Personality, 40, 1137-1151.

Ptacek, J. T., Smith, R. E., \& Zanas, J. (1992). Gender, appraisal, and coping: A longitudinal analysis. Journal of Personality, 60(4), 747-770.

Rexrode, K. R., Peterson, S., \& O’Toole, S. (2008). The Ways of Coping Scale: A reliability generalization study. Educational and Psychological Measurement, 68(2), 262-280.

Riemer, H. A., \& Chelladurai, P. (1998). Development of the Athlete Satisfaction Questionnaire (ASQ). Journal of Sport \& Exercise Psychology, 20(2), 127-156.

Rosenbaum, M. (1980). A schedule for assessing self-control behaviors: Preliminary findings. Behavior Therapy, 11, 109-121.

Smith, R. E., Schutz, R. W., Smoll, F. L., \& Ptacek, J. T. (1995). Development and validation of a multidimensional measure of sport-specific psychological skills: The Athletic Coping Skills Inventory-28. Journal of Sport \& Exercise Psychology, 17(4), 379-398.

Smith, R. E., Smoll, F. L., \& Schutz, R. W. (1990). Measurement and correlates of sport-specific cognitive and somatic trait anxiety: The sport anxiety scale. Anxiety Research, 2(4), 263280.

Tamminen, K. A., \& Holt, N. L. (2010). Female adolescent athletes' coping: A season-long investigation. Journal of Sport Sciences, 28, 101-114.

Thurrell, R. (2010). Development of a tactical-level full range leadership measurement instrument (Unpublished master's thesis). Air Force Institute of Technology, Wright Patterson Air Force Base, $\mathrm{OH}$. 
Todd, S., \& Kent, A. (2004). Perceptions of the role differentiation behaviors of ideal peer leaders: A study of adolescent athletes. International Sports Journal, 8, 105-118.

van Teijlingen, E. R., \& Hundley, V. (2001, Winter). The importance of pilot studies. Social Research Update, 35, 1-4.

Vincer, D. J. E., \& Loughead, T. M. (2010). The relationship among athlete leadership behaviors and cohesion in team sports. The Sport Psychologist, 24, 448-467.

Vitaliano, P. P., Russo, J., Carr, J. E., Maiuro, R. D., \& Becker, J. (1985). The Ways of Coping Checklist: Revision and psychometric properties. Multivariate Behavioral Research, 20, $3-26$.

Voelker, D. K., Gould, D., \& Crawford, M. J. (2011). Understanding the experience of high school sports captains. The Sport Psychologist, 25, 47-66.

Walen, S., DiGuiseppe, R., \& Dryden, W. (1992). A practitioner's guide to rational-emotive therapy. New York, NY: Oxford University Press.

Watson, D., Clark, L. A., \& Tellegen, A. (1988). Development and validation of brief measures of positive and negative affect: The PANAS scales. Journal of Personality and Social Psychology, 54(6), 1063-1070.

Welle, P. D., \& Graf, H. M. (2011). Effective lifestyle habits and coping strategies for stress tolerance among college students. American Journal of Health Education, 42(2), 96-105.

Weinberg, R. S., \& Gould, D. (2011). Foundations of Sport and Exercise Psychology (5 ${ }^{\text {th }}$ ed.) Champaign, IL: Human Kinetics.

Weiss, M. R., Bredemeier, B. J., \& Shewchuk, R. M. (1985). An intrinsic/extrinsic motivation scale for the youth sport setting: A confirmatory factor analysis. Journal of Sport Psychology, 7, 75-91. 
Widmeyer, W.N., Brawley, L.R. \& Carron, A.V. (1985). The measurement of cohesion in sport teams: The Group Environment Questionnaire. London, ON: Sport Dynamics.

Yi, J. P., Smith, R. E., \& Vitaliano, P. P. (2005). Stress-resilience, illness, and coping: A personfocused investigation of young women athletes. Journal of Behavioral Medicine, 28(3), $257-265$.

Yoo, J. (2001). Coping profiles of Korean competitive athletes. International Journal of Sport Psychology, 32, 290-303.

Zacharatos, A., Barling, J., \& Kelloway, E. K. (2000). Development and effects of transformational leadership in adolescents. Leadership Quarterly, 11(2), 211-226.

Zhang, J., Jensen, B. E., \& Mann, L. (1997). Modification and revision of the leadership scale for sport. Journal of Sport Behavior, 20, 105-122. 